\title{
A Detailed Investigation of the Bond Performance of Basalt Fiber-Reinforced Polymer Bars in Geopolymer Concrete
}

\author{
Sarwar Hasan Mohmmad ${ }^{1,2^{*}}$, Mehmet Eren Gülşan ${ }^{2 *}$, Abdulkadir Çevik $^{2}$ \\ ${ }^{1}$ Department of Civil Engineering, Sulaimani Polytechnic University, Qrga, Wrme Street 327/76, Sulaimani, Iraq \\ ${ }^{2}$ Department of Civil Engineering, Gaziantep University, Üniversite Bulvarı 27310 Şehitkamil - Gaziantep, Turkey \\ * Corresponding author, e-mail: sarwar.hasan@spu.edu.iq, gulsan@gantep.edu.tr
}

Received: 25 July 2021, Accepted: 03 February 2022, Published online: 10 February 2022

\begin{abstract}
This comprehensive experimental study aimed to determine the bond performance of basalt fiber reinforced polymer (BFRP) bars in geopolymer concrete (GC). The study examined the bond performance of BFRP bars and GC by considering several parameters, including bar diameters of 8,10, and $12 \mathrm{~mm}$, embedment lengths of 4, 8, and $12 \mathrm{~d}_{b} \mathrm{~mm}$ (where $\mathrm{db}$ is the diameter of the bar), concrete covers of 20,40, and $70 \mathrm{~mm}$ and compressive strengths of 21.7 and $34.4 \mathrm{MPa}$. The study also compared the effect of the bar surface and bar type on GC bond performance. Eventually, the results were compared with ordinary concrete (OC). The obtained results indicated that an increase in the BFRP bar diameter results in a decrease in the average bond stress. Similarly, an increase in the length of the bond leads to a reduction in the bond stress. The specimen possessing a short embedment length failed due to bar pullout, while the specimens with a longer embedment length failed as a result of concrete splitting. The outcomes also showed that the strength of bond increases with an increase in compressive strength and cover thickness. Furthermore, the results also indicated that BFRP-reinforced GC has comparable bond performance to steel-reinforced GC and BFRP-reinforced OC and performed better than OC. Last, Comparisons between the existing bond-slip models were offered to demonstrate the best bond stress-slip model for FRP bars and GC for ascending branch up to ultimate bond stress of the bond slip curves and for whole curves.
\end{abstract}

Keywords

BFRP, Bond stress, concrete cover, embedment length, fiber-reinforced polymer, geopolymer concrete, GFRP, pullout, slip

\section{Introduction}

Concrete based on cement and containing internal steel reinforcement is among the most preferred composite raw materials in civil infrastructure. However, various issues have arisen regarding its usage, making most researchers and constructors search for other alternatives. Due to the increase in global warming, cement usage is not encouraged because of its production process, which consumes a large amount of energy, resulting in severe environmental effects. Researchers have reported that manufacturing a single ton of cement consumes about one ton of raw materials and produces a large amount of carbon dioxide $\left(\mathrm{CO}_{2}\right)$ released to the environment [1]. Additionally, there are various substandard and deteriorated structures, which require a high cost of rehabilitation or repair and sometimes require a total replacement. In addition, the corrosion of the steel bar is associated with many effects on the serviceability as well as durability of traditional reinforced concrete structures. Various studies have explained that the corrosion of steel bars in reinforced concrete structures minimizes the tensile strength of bars due to a reduction in the cross-sectional area and a reduction in the bond between the steel bar and the surrounding concrete [2]. These issues have motivated scientists and engineers to discover other alternatives for both OC and steel reinforcement to increase sustainability. The solutions being used are substituting cement-dependent concrete with GC and the use of fiber reinforced polymer (FRP) bars instead of steel bars.

Geopolymers, which are environmentally friendly binders, are obtained by an alkaline solution that activates aluminosilicate materials, such as metakaolin, fly ash and slag. Geopolymers have, therefore, attracted considerable attention in recent years as an alternative to Portland cement $[3,4]$. Geopolymer binders usually minimize the release of greenhouse gases and energy requirements with the effective use of byproducts from industries. In addition 
to the reduction in the carbon footprint, the use of industrial byproducts, which include disposable fly ash, saves most of the unused raw materials, which would be used in the production of concrete. Moreover, different eligible features of GC have also been reported in the literature, such as fire and acid resistance, dimensional stability, and rapid development of mechanical strength. Moreover, the required material cost of fly ash-based geopolymer concrete is approximately $10-30 \%$ lower than that of OC [3]. Even though GC possess more excellence with its behavior and performance, its curing methods and utilization of alkaline solution in concrete require more skilled labors and practice. Moreover, it's a little difficult to control impurities of binder (fly ash and slag). Apart from this, drying shrinkage, efflorescence are the most common problems. The deficiency of standard mix design procedure is also challenging for many supervisors and practical engineers when required with huge volume of concrete compared to OC. GC of very high strength grade (above $80 \mathrm{MPa}$ grade) is difficult to handle and place due to higher cohesion and significantly shorter setting time [5].

Substitution of steel bars with FRP bars as the reinforcement of reinforced concrete structures is entirely acceptable to promote durability and to increase serviceability. FRP composite materials are usually resistant to corrosion, nonmagnetic, and durable [6]. Materials used in FRPs possess lower ductility and bonding strength and anisotropic properties compared to steel bars. The most used FRP reinforcing bars for concrete structures are usually made of glass (GFRP), carbon (CFRP), and aramid (AFRP). The newly manufactured type of reinforcing bars made of basalt fiber has captured considerable interest as an excellent alternative to other bars due to its efficiency and low prices. In addition, it is suitable for easy processing and is also resistant to high temperatures, vibration, impact loading, corrosion and acids [7]. BFRP has been used as a reinforcement for emerging concrete structures as a result of these outstanding properties. Although it possesses the ability to substitute carbon and glass composites in reinforced concrete structures, BFRP reinforcement is not among the already approved types of FRP in the majority of the design codes, as there is a lack of sufficient research [8].

Bringing together the several beneficial features of FRP and GC provides an essential technology in the construction field. It is difficult for reinforced GC to be widely accepted in industry. Therefore, its bond with FRP bars should be thoroughly evaluated, since it is an essential feature that affects strength and durability. Good bond performance should be available between the FRP bar and GC to successfully transmit stress from one to another and to acquire a composite action. The mechanical interlocking between ribs of deformed bars and the concrete performs a fundamental function regarding the transmission of forces accompanied by chemical adhesion and friction between the surrounding concrete and the bar [9]. Chemical adhesion and friction controlled the force transfer mechanism for sand-coated FRP bars, according to Antonietta Aiello et al. [10], with mechanical interlocking providing a significant contribution to deformed bars. Various progressive researches on the stress transmission mechanism via the bond performance between OC and FRPs were undertaken by Wei et al. [9], Lin and Zhang [11], and De Lorenzis et al. [12]. The bonding performance of various types of FRP bars in OC was investigated. The bond-slip curve was found to be similar in all of these investigations. However, recent developments in FRP research have indicated that the bond between FRPs and concrete depends on various factors. Such factors include embedment length, diameter, location and roughness of the surface of the FRP bars, compressive strength, cover, and confinement provided by the transverse reinforcement [13-16].

Solyom and Balázs [17] conducted a thorough experimental investigation on the impact of surface features on the bonding performance of FRP bars in concrete. It was discovered that the bond stress-slip behavior, bond strength, and failure mode all vary significantly depending on the surface characteristics. Vilanova et al. [18] investigated the bond slip of FRP bars in concrete under long-term loads. In comparison to the lowest concrete strength, the specimens with the highest concrete compressive strength demonstrated a lesser loss of bond stresses towards the loaded end (for short and long bond lengths). Furthermore, the findings of Mosley et al. [19] indicate that steel reinforcement achieves much better bond strength than FRP reinforcement and that the reinforcement modulus of elasticity is an essential variable impacting bond strength. the impact of air-entraining admixtures (AEA) on the bond performance of FRP bars to concrete with different compressive strengths were undertaken by Solyom and Balázs [20], the statistical significance of the influence of AEA on bond features was determined, yielding a reduction factor to account for the effect of AEA on bond strength. The test results indicate that the bond strength of FRP bars in Air-Entrained Concrete (AEC) was statistically considerably lower than 
in OC. However, the reduction is minor that it could be accounted for during the design stage by simply increasing the development length of reinforcement.

Research on the bond mechanics between GC and the deformed steel bar was initiated and authorized by Sofi et al. [21]. The researchers indicated that inorganic polymer concrete (IPC) bonds were similar to ordinary Portland cement-based concrete. Therefore, steel and IPC combinations may be applied to resist tensile and compressive stresses. Sarker [22] compared the bond strength of GC with that of OC. As a result of the comparison, the researcher concluded that although OC and GC possessed the same compressive strength, the bond performance of GC was higher than that of OC. The difference was a result of the higher tensile strength of GC. In a different study, Selby [23] explained that the bond strength of GC possessed almost the same strength as that of OC on a relative basis. Additionally, the researcher also explained that the GC had chemical adhesion, which was twice that of OC. Therefore, good chemical adhesion would hinder the early improvement of interfacial cracks between FRP bars and the concrete, as well as between longitudinal cracks and the nearby concrete.

The majority of the previous researches dealt with FRP OC bonds, steel-GC, and also steel-OC. However, there are few studies regarding bonding performance between FRP bar and GC. The study carried out by Maranan et al. [24] is one of them and is related with the bond performance between FRP and GC. The researchers investigated the bond performance of GC reinforced by the sand-coated glass Fiber-reinforced polymer (GFRP) bars and also made a comparison with $\mathrm{GC}$ reinforced by steel bar. The results obtained by the authors indicated that GC reinforced by the sand-coated GFRP possessed the comparable bond strength with that of GC reinforced by steel bar. An almost similar phenomenon was also obtained by Tekle et al. [25]. Since the application of BFRP composites has been in civil engineering only for some years, BFRP related studies regarding fundamental physic-chemical characteristics and bond performance are quite limited. This lack of overall understanding of the BFRP composites will prevent its broad and safe usage. Moreover, no research has been performed on the bond behavior between the BFRP and the GC which is the fundamental motivation of this study.

This paper presents a comprehensive and detailed experimental study on the bond performance between GC and BFRP bars. Direct pullout tests were implemented by the consideration of several factors that affect the bond strength, including embedment length, type and diameter of FRP bars, surface configuration of the bar, concrete type, concrete cover thickness, and compressive strength. Moreover, the outcomes were compared with those of GC reinforced by steel bars to promote the acceptability of BFRP as an efficient alternative to steel reinforcement for GC.

\section{Experimental program}

\subsection{Materials}

\subsubsection{Geopolymer concrete}

The used GC consisted of fine and coarse aggregates, superplasticizer, water, and a geopolymer paste made from the chemical activation of two industrial by-products ground granulated blast furnace slag (GGBFS) and Class F fly ash (FA) using an alkaline activating solution. The slag and fly ash obtained from Iskenderun and Adana (Turkey), were used as binder, and they were compatible with the ASTM C989-05 [26] and ASTM C618 [27] standards, respectively. The alkaline activator was based on combination of sodium hydroxide $(\mathrm{NaOH})$ and sodium silicate $\left(\mathrm{Na}_{2} \mathrm{SiO}_{3}\right)$. The sodium hydroxide was in the form of a flake and its purity was $98 \%$, while $\mathrm{Na}_{2} \mathrm{SiO}_{3}$ comprised 13.7\% Na2O, 29.4\% $\mathrm{SiO} 2,55.5 \% \mathrm{H} 2 \mathrm{O}$ and its modulus (Ms) was equivalent to 2.14, (where $\mathrm{Ms}=\mathrm{Si2O} / \mathrm{Na} 2 \mathrm{O}$ ). The river aggregates whose largest particle sizes are $4 \mathrm{~mm}$ and $12 \mathrm{~mm}$ were utilized for fine and coarse aggregates, respectively. The sieve analysis of aggregates and the physical properties were measured and illustrated in Table 1, according to ASTM C127 [28]. Moreover, a latest generation of polycarboxylic-dependent superplasticizer (SP), was used in the different mixtures. A Portland cement (PC) based on Turkish standard was also used during the study to produce ordinary concrete for comparison with GC. Additionally, the chemical and physical properties of GGBFS, PC and FA are summarized in Table 2.

\subsubsection{Reinforcing bars}

In the study, three types of reinforcing materials were utilized. The types consisted of BFRP, GFRP as well as deformed steel bars. Both BFRP and GFRP reinforcing bars were produced through the protrusion process of continuous fibers immersed in a vinyl resin and contained at least $65 \%$ fiber volume ratio. As shown in Fig. 1, for BFRP three different diameters 8,10 , and $12 \mathrm{~mm}$ were considered, while for GFRP and steel bars only one diameter (10 mm) was adopted to make comparison with BFRP bars. As indicated by the manufacturer, the geometric and guaranteed properties of FRP bars are given in Table 3. The elastic 
Table 1 Physical properties and sieve analysis of course and fine aggregates

\begin{tabular}{|c|c|c|c|c|c|c|c|c|c|c|}
\hline Sieve Size (mm) & 16 & 8 & 4 & 2 & 1 & 0.5 & 0.25 & Fineness Modules & Specific Gravity & Absorption \\
\hline Fine Aggregate & 100 & 100 & 87.1 & 51.4 & 32.3 & 15.8 & 4.1 & 2.36 & 2.55 & 3.2 \\
\hline Coarse Aggregate & 100 & 67.9 & 3.2 & 0 & 0 & 0 & 0 & 5.57 & 2.61 & 1.8 \\
\hline
\end{tabular}

Table 2 Physical properties and Chemical composition of fly ash, slag, and PC

\begin{tabular}{|c|c|c|c|c|c|c|c|c|c|c|c|}
\hline Component & $\mathrm{CaO}$ & $\mathrm{Na}_{2} \mathrm{O}$ & $\mathrm{K}_{2} \mathrm{O}$ & $\mathrm{SiO}_{2}$ & $\mathrm{Fe}_{2} \mathrm{O}_{3}$ & $\mathrm{Al}_{2} \mathrm{O}_{3}$ & $\mathrm{MgO}$ & $\mathrm{SO}_{3}$ & $\begin{array}{l}\text { Specific } \\
\text { Gravity }\end{array}$ & $\begin{array}{l}\text { Loss on } \\
\text { Ignition }\end{array}$ & $\begin{array}{l}\text { Blaine Fineness } \\
\qquad\left(\mathrm{m}^{2} / \mathrm{kg}\right)\end{array}$ \\
\hline Fly ash (\%) & 2.24 & 0.38 & 3.37 & 57.2 & 7.1 & 24.4 & 2.4 & 0.29 & 2.15 & 1.52 & 379 \\
\hline Slag (\%) & 34.12 & 0.35 & 0.97 & 36.4 & 0.69 & 10.39 & 10.3 & 0.49 & 2.79 & 1.64 & 418 \\
\hline PC (\%) & 62.12 & 0.17 & 0.88 & 19.7 & 2.88 & 5.16 & 1.17 & 2.63 & 3.15 & 2.99 & 326 \\
\hline
\end{tabular}

modulus and the tensile strength were also measured by the use of a nominal cross-sectional area. Moreover, The BFRP bars having $10 \mathrm{~mm}$ diameter, consisted of various surface conditions (cross helically wrapped (BCHW), ribbed (BR), and sand coated surfaces (BS), as shown in Fig. 1 .

\subsection{Mix proportions}

Geopolymer concrete is a relatively new invention. As a result, there is no standard mix design for GC. To obtain a target compressive strength of 20 and $35 \mathrm{MPa}$, different trail mixes were performed, the concrete mix proportions are shown in Table 4. The alkaline activator used in the manufacture of $\mathrm{GC}$ comprised of $\mathrm{NaOH}$ and $\mathrm{Na}_{2} \mathrm{SiO}_{3}$ solutions. A solution of sodium silicate was mixed with a $12 \mathrm{M}$ solution of $\mathrm{NaOH}$ at least 24 hours before casting [1]. The $\mathrm{NaOH}$ pellets, which were commercially available with purity of about $98 \%$, were melted in water to obtain the $12 \mathrm{M} \mathrm{NaOH}$ solution. For economic purposes and uses, the ratio of $\mathrm{Na}_{2} \mathrm{SiO}_{3}$ to $\mathrm{NaOH}$ lay within the range of $1.5-2.5,[29]$ and thus the ratio of 2.5 was used in the study, while that of liquid to binder was 0.5 .

At the initial mixing stage, the coarse and fine aggregates were mixed with each other for approximately 2 minutes before the addition of binder materials. Then the dry ingredients were also combined in a pan mixer having a volume of about 80 liters for other 2 minutes. Additionally, the alkali activator, superplasticizer, and also extra water were gradually put to the mixture, and the process progressed for a maximum of another 3 minutes. Afterwards, newly manufactured concrete was mixed for another 2 minutes in order to ensure uniformity and homogeneity.

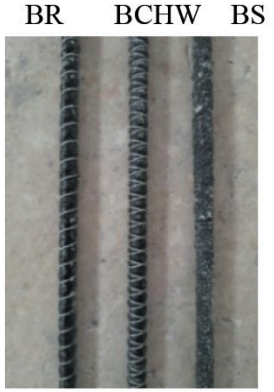

(a)

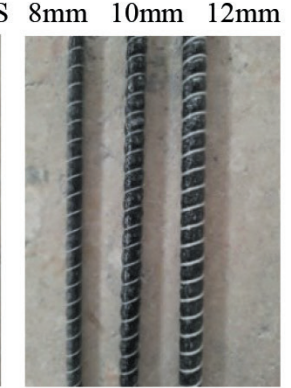

(b)

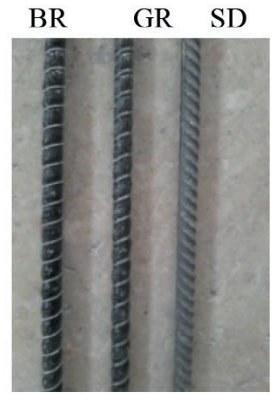

(c)
Fig. 1 (a) different BFRP surface condition; (b) different BFRP bar diameter; (c) Different reinforcement bar

Table 3 Guaranteed properties of FRP and steel reinforcing bars as reported by the manufacturer

\begin{tabular}{lcccc}
\hline Reinforced bars & $\emptyset_{f}(\mathrm{~mm})$ & $A_{f}\left(\mathrm{~mm}^{2}\right)$ & $F_{f u}(\mathrm{MPa})$ & $E_{f}(\mathrm{GPa})$ \\
\hline BFRP & 8.0 & 50.27 & 1152 & $48 \pm 2.5$ \\
BFRP & 10 & 78.54 & 1146 & $48 \pm 2.5$ \\
BFRP & 12 & 113.1 & 1143 & $47 \pm 2.5$ \\
GFRP & 10.0 & 78.54 & 1020 & $40 . \pm 2.5$ \\
steel & 10.0 & 78.54 & 565 & 200 \\
\hline
\end{tabular}

$\sigma_{f}:$ Bar diameter, $A_{f}:$ nominal cross-sectional area, $F_{f u}^{b}$ : Guaranteed tensile strength, $E_{f}$ : Modulus of elasticity

Table 4 Mix proportion of the concrete and concrete strength

\begin{tabular}{|c|c|c|c|c|c|c|c|c|c|c|c|c|c|}
\hline Mix & Fly Ash & Slag & cement & Fine Agg. & $\begin{array}{c}\text { Coarse } \\
\text { Agg. }\end{array}$ & $\mathrm{Na}_{2} \mathrm{SiO}_{3}+\mathrm{NaOH}$ & Water & SP & $\begin{array}{c}\mathrm{Na}_{2} \mathrm{SiO}_{3} / \\
\mathrm{NaOH}\end{array}$ & $\begin{array}{c}\text { Alkali / } \\
\text { Binder }\end{array}$ & $w / c$ & $\begin{array}{l}f c^{\prime d a} \\
(\mathrm{MPa})\end{array}$ & $\begin{array}{c}f^{d a} \\
(\mathrm{MPa})\end{array}$ \\
\hline GC35 & 225 & 225 & - & 683.4 & 835.3 & 225 & 40.5 & 27 & 2.5 & 0.5 & - & 34.4 & 3.27 \\
\hline GC20 & 320 & 80 & - & 709 & 868 & 200 & 42 & 24 & 2.5 & 0.5 & - & 21.7 & 2.1 \\
\hline $\mathrm{OC}$ & - & - & 440 & 665 & 1225 & - & 198 & 2.38 & - & - & 0.45 & 33.6 & 3.12 \\
\hline
\end{tabular}

Note: All amounts are based on $\mathrm{kg} / \mathrm{m}^{3}$, except Alkali/Binder $\mathrm{Na}_{2} \mathrm{SiO}_{3} / \mathrm{NaOH}$, and $w / c ;{ }^{\mathrm{d}}$ Based on $100 \mathrm{~mm} \times 200 \mathrm{~mm}$ cylinder testing; ${ }^{\mathrm{a}}$ avera 


\subsection{Experimental matrix}

Table 5 gives summary and average test results of the 38 tested specimens in detail. The study considered three bar types which were BFRP, steel, and GFRP bars. BFRP bars possessed diameters of $8,10,12 \mathrm{~mm}$ and a ribbed surface with different embedded lengths, while both GFRP and steel bar had diameter of $10 \mathrm{~mm}$ and ribbed surface. The $10 \mathrm{~mm}$ diameter of BFRP bars comprising various surface conditions was also adopted as a different variable. The concrete's cover thickness with three values (20,40, and $70 \mathrm{~mm}$ ) was also considered. Two compressive strength values of 21.7 and $34.4 \mathrm{MPa}$ were also taken into consideration in order to determine the effect of concrete strength on bond behavior. The total number of pullout specimens was 38 and classified to 19 different sets, for each set two nominally identical specimens were tested to obtain more accurate results. In addition, to perform the analysis of the results, the concrete splitting tensile strength and the compressive strength tests were performed.

The designation of tested specimens comprises of two parts. The first part shows the concrete' details with the first two letters representing the type of concrete, whereby OC and GC (ordinary concrete and geopolymer concrete), respectively. The next two numbers indicate the compressive strength in $\mathrm{MPa}$ and the concrete cover in terms of $\mathrm{mm}$. The second part shows bar details with the first letter representing the type of bar where $\mathrm{G}, \mathrm{S}$, and $\mathrm{B}$ represent GFRP, steel, and BFRP bars, respectively. The second letter also shows the bar surface's condition as CHW, R, and $\mathrm{S}$ standing for cross helically wrapped, ribbed, and sand coated surfaces, respectively. The next number demonstrates the diameter of the bars in $\mathrm{mm}$, while the following number shows the embedment length regarded as 4,8 , and 12 times the bar's diameter and the last number shows the number of the sample. For example, the specimen $\mathrm{GC} / 34 / 70-\mathrm{BR} / 8 / 8 \mathrm{~d}-1$ is geopolymer concrete specimen with a $34 \mathrm{MPa}$ compressive strength and $70 \mathrm{~mm}$ cover, and it is reinforced with basalt ribbed bar with $8 \mathrm{~mm}$ diameter, embedment length is $8 \mathrm{db}$, and specimen number is one for its group.

\subsection{Process of specimen production}

Processing details of GC and the specimen preparation are shown in Fig. 2. Different pull out tests were achieved depending on the standards of ACI440.3R-04 [30] and also CSA-S806-12 [31]. According to the CSA-S806-12 [31], the appropriate size of the concrete cube is $150 \mathrm{~mm}$. These pullout specimens consisted of a FRP bar which was horizontally put into the cubic plywood molds of $150 \times$ $150 \times 150 \mathrm{~mm}$ to obtain a concentric alignment. A polypropylene tube was utilized to separate the FRP bar and geopolymer bond. The bar was extended for a length of up to $50 \mathrm{~mm}$ outwards from the concrete cube to estimate the free end slippage. The GC was put into cubic molds and compacted by a mechanical vibrator that minimized the available air voids, specifically close to the bonding region. Upon completing the casting process, the specimens were covered with plastic membrane covers to reduce the alkaline solution's evaporation. The casted samples were placed under laboratory conditions for a whole day. The specimens and corresponding cylinder specimens were removed from molds after 24 hours and the specimens of GC were cured at a favorable temperature of $23{ }^{\circ} \mathrm{C}$ in the laboratory until the $28^{\text {th }}$ day. On the other hand, the specimens of the OC were cured in a water tank up to the same date.

Different steel tubes containing a diameter of $35 \mathrm{~mm}$ and a thickness of $4.8 \mathrm{~mm}$ were sleeved at the FRP bars' ends with the epoxy adhesive before commencing of the testing to protect FRP bars from the gripping force of the machine's clamps during pull out tests, as shown in Fig. 3. This ensures that the bond failure will be obtained instead of the bar failure since, unlike steel, transverse strength of BFRP bars is not as high as their longitudinal strength.

\subsection{Test methods}

According to ACI 440.3R-04 [30], the direct pullout tests were utilized in this research to examine the performance of the FRP-reinforced GC bond. The arrangement of the pullout test was shown in Fig. 3. The concrete specimens were put in a well-manufactured steel frame in the machine for testing. In addition, two linear variable displacement

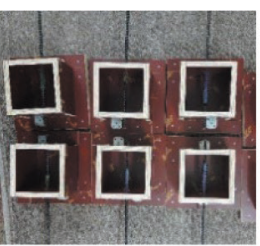

(a)

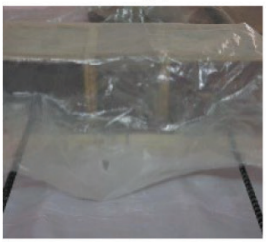

(d)

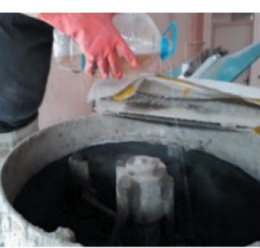

(b)

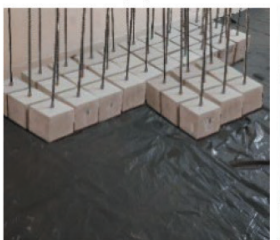

(e)

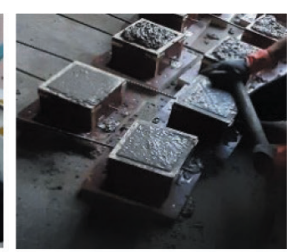

(c)

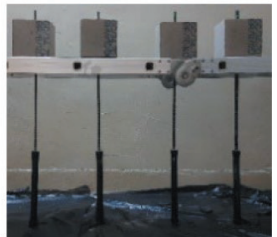

(f)
Fig. 2 Geopolymer concrete specimens: (a) specimen molds; (b) dry mixing and addition of activator; (c) filling and vibrating; (d) curing; (e) pull-out specimens; and (f) specimens with anchor 
transducers (LVDT) were attached near the loaded side of FRP bars by using steel racks to record the bar slip associated with the top concrete's surface. Other LVDT was connected to the free end of FRP bars that protruded outside of the concrete cube. Specimens were tested in a computer controlled universal testing machine containing load capacity of $500 \mathrm{kN}$. The tensile load was directly applied to the bar through a displacement control mode with a rate of $1 \mathrm{~mm} / \mathrm{min}$ based on the ACI 440.3R-04s standard rules. The tests were carried on until the slip of the loaded end reached almost $15 \mathrm{~mm}$. During the process of testing, the load and the readings of the slip were recorded by a data acquisition system with a constant rate of four readings per second.

\subsection{Measurements analysis}

The measurements of the experimental study comprised of free as well as loaded end slips, and even the corresponding load resulted from data logger at an average rate of four readings per second. A load cell of the test machine was used to measure the load, and the obtained reading results from the LVDTs were used in the production of the curves of bond-slips for each specimen. At any loading level, bar slips at the free ends were directly attained from the readings of LVDTs. On the other hand, in the case of loaded end, the bar's elongation between the top LVDT and the beginning of the bonded zone was deducted from the measurements of LVDT at each force readings, as indicated in Eq. (1).

$\delta_{L E}=$ Top LVDT reading $-\frac{P L}{A_{b} E_{b}}$,

where $\delta_{L E}$ refers to the slip at the loaded end; $P$ refers to the measured pullout load, measured in Newtons, $E_{b}$ refers to the elasticity modulus of FRP bars, given in megapascals, while $A_{b}$ refers to the cross-sectional area of FRP bars specified in square millimeters. On the other hand, $L$ is the length between the LVDT's attachment point and the loaded side inside the concrete, as shown in Fig. 3.The distribution of stress varies along the embedment length of FRP bars. Therefore, for the pullout tests, average stress is expressed as in Eq. (2).

$$
\tau=\frac{P}{\pi d_{b} l_{b}}
$$

Where $l_{b}$ refers to the embedment length, $P$ is the pullout load, and $d_{b}$ refers to the FRP bar's diameter. The strength of the bond was determined using Eq. (2) Moreover, the ultimate pullout load, $P_{\max }$, with corresponding slip, and residual bond stress are illustrated in Table 5 .

\section{Results and discussion}

\subsection{The bonding failure mode}

Two different kinds of failure mode, the pullout of the bar, and the splitting of GC, were observed as a result of the experimental study. The pullout type of failure was observed in specimens having a short-bonded length and a small diameter of the bars. This failure usually occurs as a result of insufficient bonding development length. Therefore, the splitting tensile stress induced by bond is inadequate to develop a broader longitudinal cracking. The cracks that began at the surrounding GC (near the interface of the bar and the GC), could not pass through the outside surface. Therefore, this led to an increase in bond stress. Different researchers have explained the similar behavior for geopolymer and ordinary concrete reinforced by FRP bars [24, 32].

Moreover, the concrete splitting failure was shown by the specimens that have a more considerable embedment length, since they possess the adequate length to create

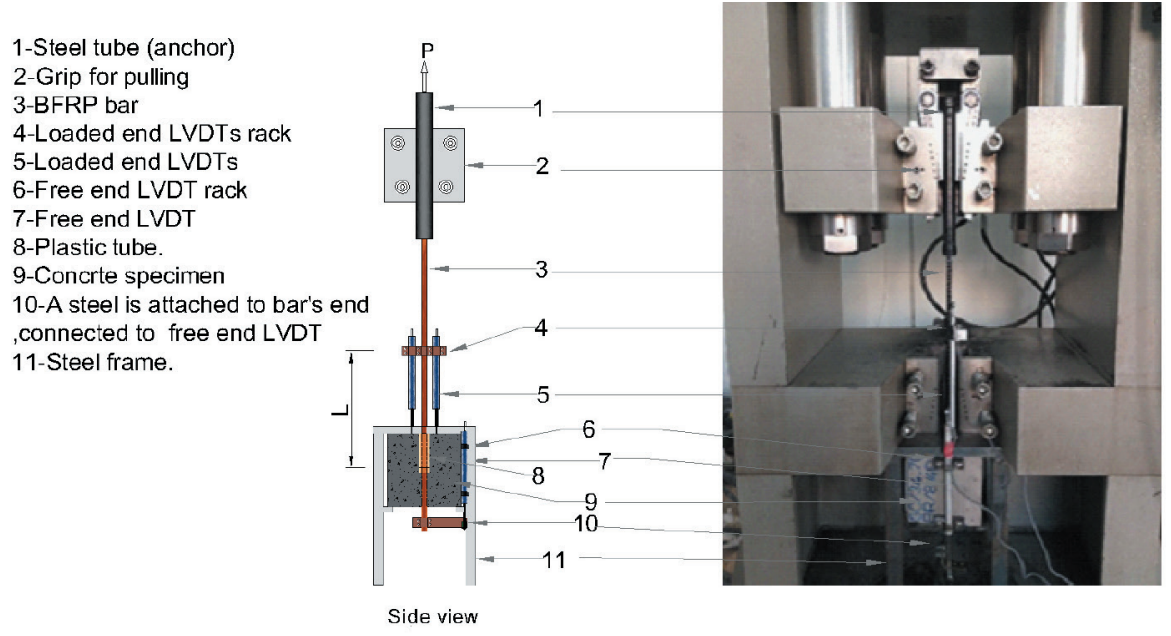

Fig. 3 Setup of pullout test schematic diagram and actual test photo 
higher radial stress. The increased amount of stress results in wider longitudinal cracks, by passing the outer concrete surface, which eliminates the confinement capacity of GC. This type of failure leads to the contamination of the specimens' real bond strength, resulting in reduced bond stress as compared to specimens, which failed due to the bars' pullout. Geopolymer concrete splitting happened in a brittle explosive manner that was observed by Sofi et al [21] and Sarker [22]. Longitudinal cracks were mostly localized in places where the BFRP was bonded to the GC.

Failure modes of the specimens containing BFRP bar of diameter $8 \mathrm{~mm}$ were shown in Fig. 4. The specimens which were embedded 4 and $8 d_{b}$ into the GC failed due to the bars' pullout, while those with $12 d_{b}$ embedment lengths failed as a result of concrete splitting. Similar observations and results were obtained in specimens having a diameter of $10 \mathrm{~mm}$ BFRP bar. Regarding the specimens containing $10 \mathrm{~mm}$ BFRP bars, specimens possessing 4 and $8 d_{b}$ bond lengths failed due to pullout, whereas the specimens whose embedment length was $12 d_{b}$ failed because of the splitting of the concrete, as indicated in Fig. 5. The failure mode of the pullout specimens possessing a $12 \mathrm{~mm}$ BFRP bar diameter was illustrated in Fig. 6. Only specimens having a very short bonded length failed due to pullout, while the rest of the specimens failed as a result of the splitting of the concrete. Based on these results, it can be concluded that an increase in the bar diameter increases the dominancy of concrete splitting in specimens possessing a longer bonded length. Moreover, longitudinal crack formation is much more in the specimens having a longer embedment length.

It was considerable to note that for the same bond length, compressive strength and the diameter of bar, difference in the surface configuration led to change in the failure mode and bond stress-slip curves. The failure mode of the ribbed surface, as well as sand coating, were both pullout failure, while that of the cross helically wrapping surface was the concrete splitting, as shown in Fig. 7. The visual evaluation demonstrated that the bars' surface layers experienced the deterioration of various magnitudes. Generally, the layers coated with sand sheared off either totally or even partially, and limited breakdowns were observed in ribbed bars, whereas the cross helically wrapping was more damaged than the ribbed bars. In addition, the ribs on the surface of the ribbed bars were partially worn in the bond region, and the concrete between the ribs was sheared off and then brought out. On the other hand, BFRP bars with cross helically wrapping ribs heavily detached from the bars, and thus the rib marks became visible on the concrete.
Furthermore, for similar bonded length, concrete cover, diameter, and surface, change in the concrete's compressive strength led to alteration in failure mode. Failure of the specimens having higher concrete's compressive strength was less brittle than those specimens having a smaller compressive strength. This was due to the reflection of the bond failure by an inter-laminar shear amongst the bars' layers more than concrete crushing $[8,33]$. The larger concrete's adhesion characteristic does not permit the separation of polymer resin from the surrounding concrete's surface and due to the FRP composites' weak adhesion characteristic as shown in Fig. 7(a). While, the specimens

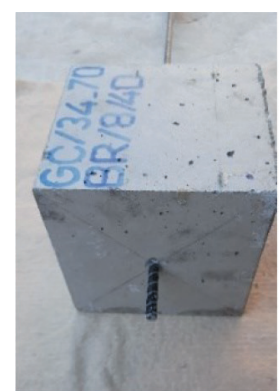

(a)

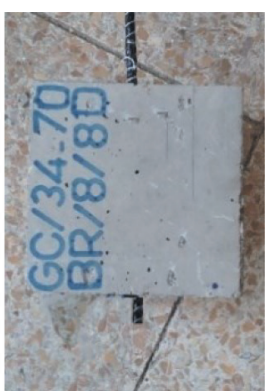

(b)

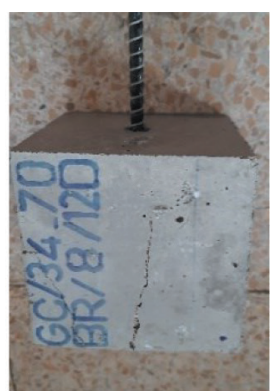

(c)
Fig. 4 Mode of failure of GC/34/70-BR/8 specimens: (a) $4 d_{b}$; (b) $8 d_{b}$; and (c) $12 d_{b}$

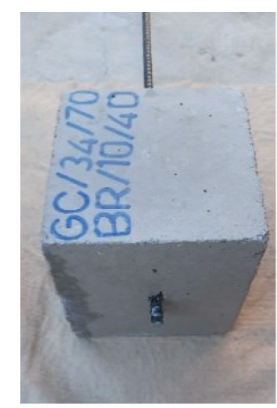

(a)

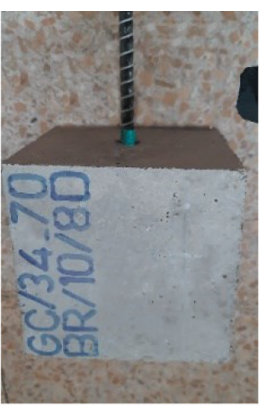

(b)

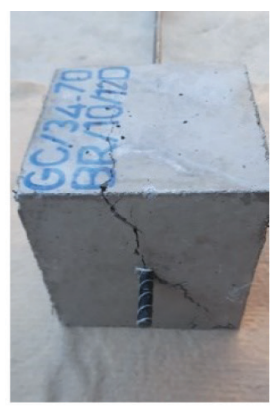

(c)
Fig. 5 Mode of failure of GC/34/70-BR/10 specimens: (a) $4 d_{b}$; (b) $8 d_{b}$; and (c) $12 d_{b}$

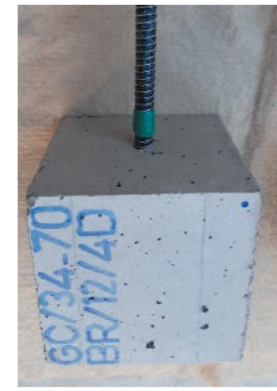

(a)

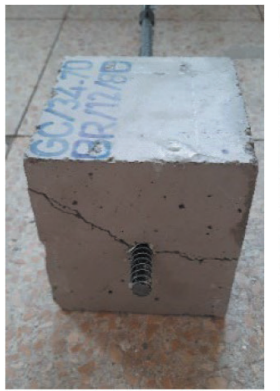

(b)

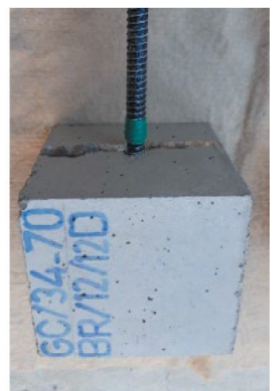

(c)
Fig. 6 Mode of failure of GC/34/70-BR/12 specimens: (a) $4 d_{b}$; (b) $8 d_{b}$; and (c) $12 d_{b}$ 
having smaller compressive strength displayed concrete crushing at the bond failure associated with fiber's surface removal partially that entirely agrees with the observations made by Lee et al. [34].

The concrete cover is another essential factor that affects failure modes as well as bond strength of BFRP bar to GC. Pull out mode failure, which did not split the cover, was observed in most of the specimens, since they had enough thickness cover of about $70 \mathrm{~mm}$ and high cover thickness improved the bar's confinement as well as the concrete cover's shear resistance. The bar's surface was peeled off, as shown in Fig. 7(a) and Fig. 8(a). For specimens possessing 20 and $40 \mathrm{~mm}$ cover thickness, the splitting failure occurred before the pull-out failure because their concrete cover was not enough to induce sufficient shear resistance as well as confinement to the reinforcing bars, as indicated in Fig. 8(b) and (c).

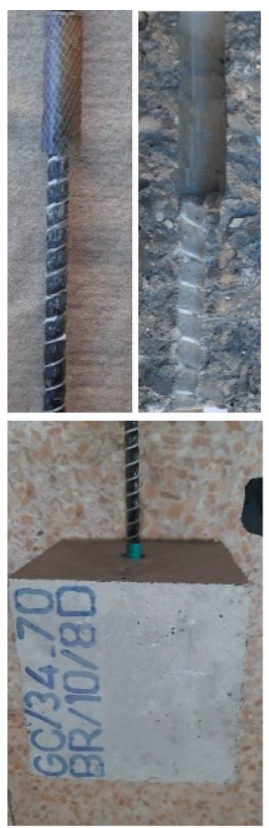

(a)
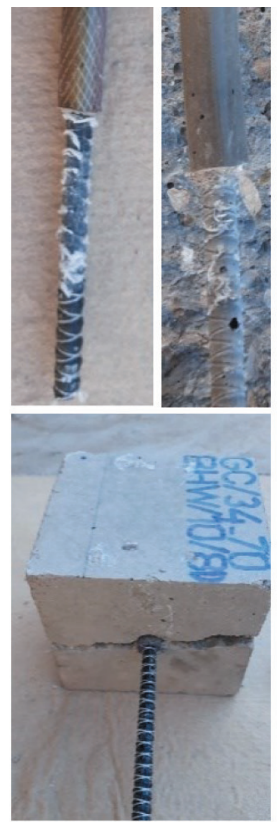

(b)
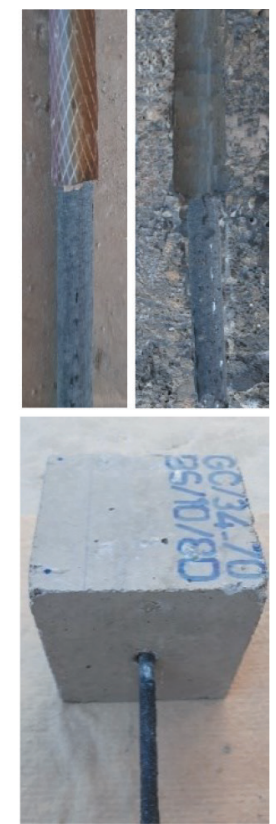

(c)

Fig. 7 Bond failure surface of FRP bars: (a) BR; (b) BCHW; and (c) BS

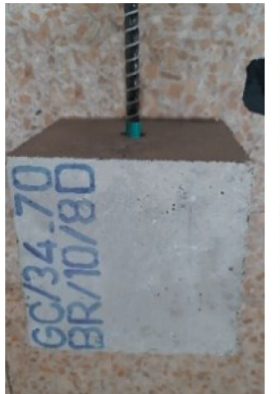

(a)

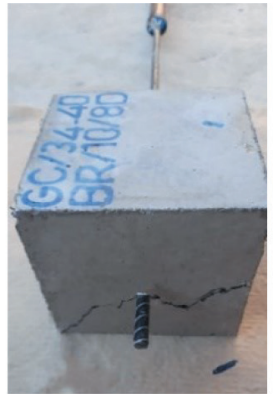

(b)

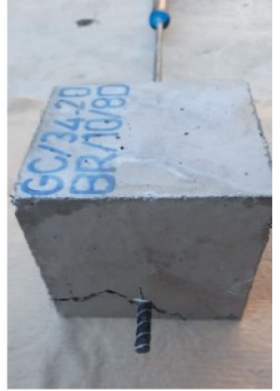

(c)

Fig. 8 Failure pattern for different concrete covers: (a) $70 \mathrm{~mm}$; (b) 40 $\mathrm{mm}$; and (c) $20 \mathrm{~mm}$

For GC/34/70-BR/10/8d, GC/34/70-GR/10/8d, and $\mathrm{GC} / 34 / 70-\mathrm{SD} / 10 / 8 \mathrm{~d}$, whose types of reinforcement were different only, the pullout failure was the only bond failure mode. Besides, no splitting cracks signs occurred on the cube specimens. However, bonding failure mechanisms displayed some differences. For instance, whenever there was enough confinement in deformed steel bar at the time of pullout, shear cracks appeared between surrounding concrete and the bar ribs before failure of the bar through the pullout mode. Whenever this type of failure occurred, the bar's bond load usually relied on the nearby concrete's strength. However, for the specimens having FRP bars, the bond failure partially happened on the bar's surface and on the concrete through peeling part of the surface layer.

\subsection{Bond stress-slip relationship curves}

Bond stress-slip relation was used to explain the bond performance of BFRP bars inserted into the GC, since it is a widely used representation technique for the bond behavior of reinforcement inside the concrete members. Different relationships of bond stress and slip behavior of the representative BFRP specimens containing various values of diameters and bond lengths at the free and loaded ends were shown in Fig. 9 in accordance with the already existing pattern of failure and the analysis of the mechanism, as well as the previous study results. For specimens that failed in concrete splitting, only the rising branches or just over the peak point were accepted in the bond stressslip curves as a result of the rapid failure. Moreover, bond stress-slip curves of the specimens that failed due to the pullout mode can be grouped into different phases. The phases include the micro slip (linear), nonlinear, descending and residual steps.

Micro-slip Phase: At the first loading step, the relationship is very close to linear changes. The bond between BFRP bars and GC primarily depends on the chemical adhesion and even low mechanical interlock. Since there is a small slip, the bond stress increases quickly leading to sizeable first slope. The bond-slip at the loaded end indicates a reduced stiffness as compared to the free end curve, as illustrated in Fig. 9. The differences show increase in the length of reinforcing bar between the two different positions of the slip measurements. Very high amount of stiffness was observed until the onset of the slips for the bars having a smaller diameter and the stiffness was significantly higher in comparison to those with a larger diameter. A similar behavior reported by El Refai et al. [8] for normal strength of OC with basalt and glass FRP bar. 

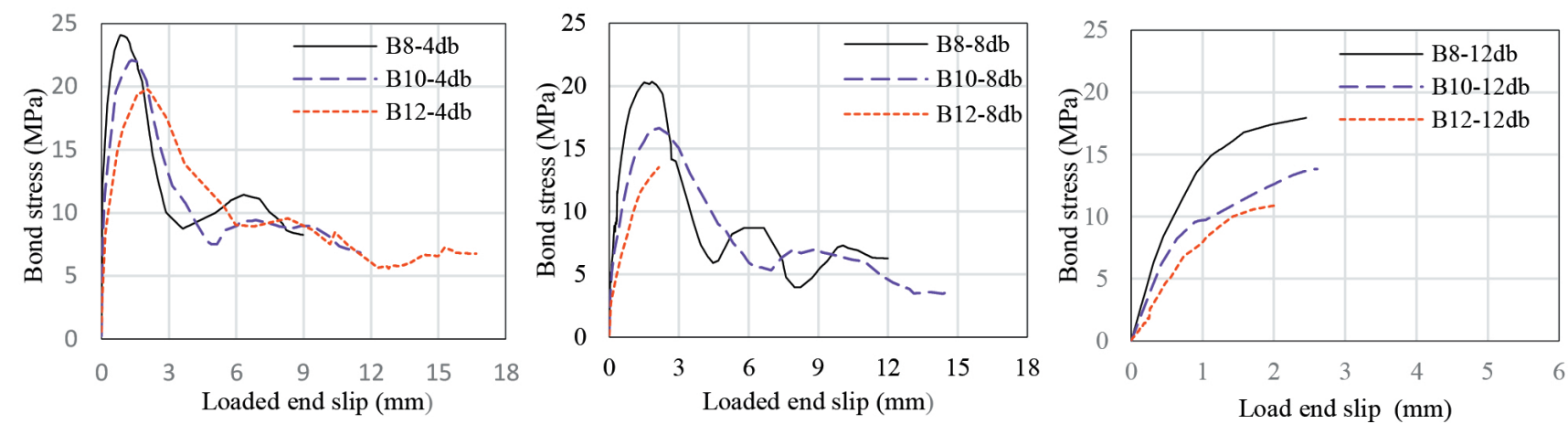

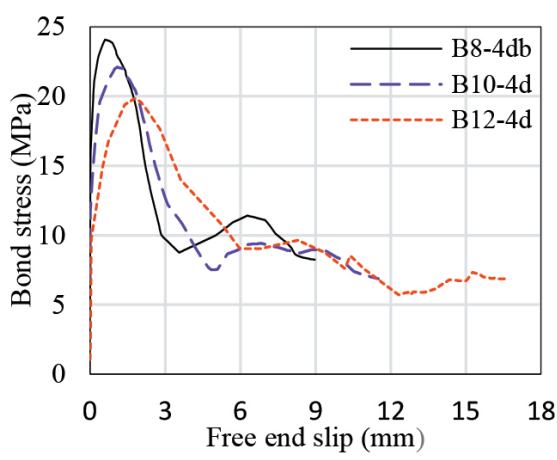

(a)

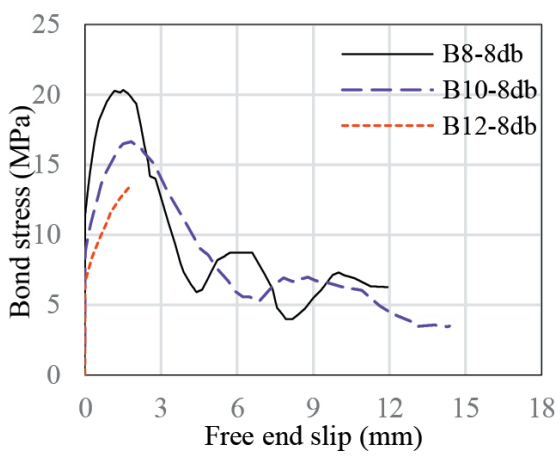

(b)

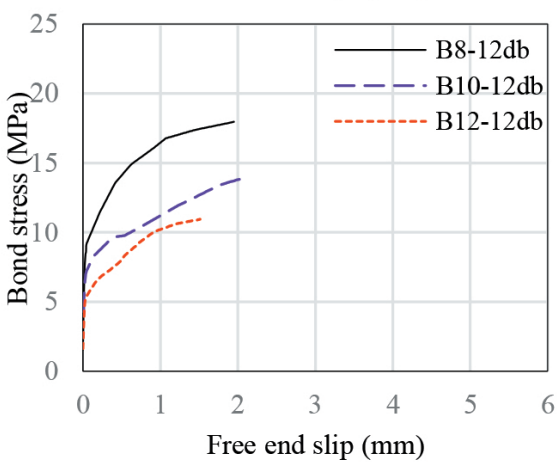

(c)

Fig. 9 bond-slip curves for BFRP bars at loaded and free ends for different diameter and embedment length (EL):

(a) $\mathrm{EL}=4 d_{b}$; (b) $\mathrm{EL}=8 d_{b}$; and (c) $\mathrm{EL}=12 d_{b}$

In addition, the thickness of the cover and the compressive strength of concrete influenced the stiffness of bond, the test results indicated that the stiffness increased with the increase of compressive strength and cover due to increase of adhesive bond strength.

Nonlinear: Moreover, a rise in the pullout load decreases stiffness of the curves and nonlinear response is observed until the peak bond stress is achieved. The progressing bond damage leads to a lower slope whenever there is an increase in the pullout load. At this phase, the bond stress entirely relies on the friction force between GCs and BFRP bars, as well as the mechanical interlock.

Decline stage: Upon reaching the optimum value, the bond stress does not completely disappear. However, it gradually reduces as the slip increases. The mechanical occlusion force reduces during this stage, while the force of friction becomes weak slowly as a result of the wearing out of the BFRP ribs which results in the abrupt increase of the slip. As the load reaches the optimum, the specimens, experiencing splitting failure, rapidly split and fail and ultimately lose their bond strength. Therefore, the bond-slip curve does not possess any descending degree and the residual phase. For the case of specimens that fail due to pullout, the bond's strength reduces from the maximum with an increasing rate, followed by damages in resin matrix and the fibers on the ribbed FRP bar's surface, till the bond's strength reaches the first valley (completing the slip of the first cycle).

Residual stress stage: Upon drop of the average bond stress to its minimum point, it begins to increase, since the damage of both surface fiber and the FRP matrix are minor, and thus the curve proceeds to the residual stress phase. During this phase, the bond stress comprises of the force of friction and mechanical interlocking force. Besides, the BFRP bars significantly slip, while the bond stress reduces in fluctuated manner like a sinusoidal function curve with decreasing amplitude. The similar behavior was observed and reported for normal concrete by Zhang et al. [33]. In general, the optimum bond stress that corresponds to the second peak was estimated as lower than $50 \%$ of the total bond strength regardless of the bar size and concrete strength [35]. In the current study the optimum bond stress, which corresponded to the next peak was approximately $25-50 \%$ of total bond strength. Therefore, it indicated that magnitude of the bond stress, which corresponded to the next peak, entirely depended on the nature of failure mechanism and the amount of bond damage. On the other hand, the residual curve illustrated a lower stiffness than the previous peaks. Residual stresses at unloaded and loaded ends are listed in Table 5. 


\subsection{Parameters affecting the bond performance}

\subsubsection{BFRP's diameter effects to the bond behavior}

The general bond-slip relationship curves of BFRP bars containing various diameters were shown in Fig. 9 while bond strengths of BFRP bars having diameters of 8,10 and $12 \mathrm{~mm}$ were compared with respect to various bonded lengths shown in Fig. 10. It can be concluded from Fig. 10 that bond strengths of bars having larger diameter were lower as compared to bars that have small diameters. The BFRP bars possessing $8 \mathrm{~mm}$ diameter indicated bond strengths of $8.2,18.2$, and $23.1 \%$ higher than those shown by the bars of $10 \mathrm{~mm}$ diameter for 4,8 , and $12 d_{b}$ embedment lengths, respectively with an average increase of $16.5 \%$. The percentages were $17.8,33.5$, and $39.0 \%$ more than the bond strength created by the bars containing $12 \mathrm{~mm}$ diameter for the same embedment lengths and the average increase was $30 \%$.

In general, the trend adheres to the results obtained by other researchers that large diameter bars have less average bond strengths as compared to those with a smaller diameter. Therefore, outcomes of the current study agrees with other different studies, which have illustrated the effect of diameter on bond strength of GFRP and CFRP bars [24, $25,36]$. This is mainly because of three different phenomena, which increase with the bar size. The initial phenomenon is the nonlinear stress distribution along the interface between the concrete and the bar that is highly pronounced for large diameter of bars, since longer bonded lengths are required [13]. Besides, Poisson's ratios reduce the bar diameter that is related to pullout load. In general, effect of Poisson's ratio is higher for the bars having larger diameters, which results in a reduced mechanical interlock as well as the friction between geopolymer and BFRP bars [36]. Additionally, the phenomenon of shear lag is used to explain the decrease of the bond strength as the bar's

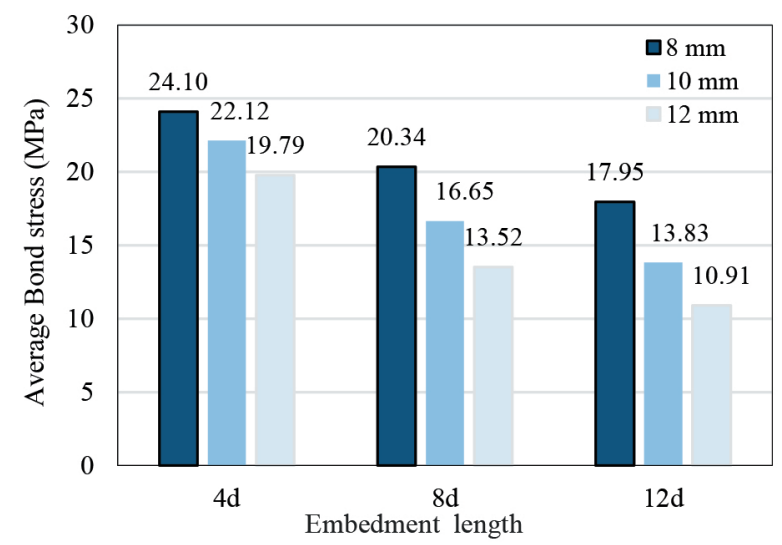

Fig. 10 Effect of bar diameter on average bond strength diameter increases. According to results obtained in other researches in which the bond behavior of FRP bars in OC had been studied $[14,36]$, a non-uniform normal stress distribution appears in the bar cross-section because of various movements between the core and the surface fibers beneath the surface tension load. As the diameter increases, the non-uniformity of stress distribution increases.

\subsubsection{Effect of embedment length}

The general trend of the test results shows that a longer embedment length results in a small value of the average bond strength. The result remains valid for all the tested specimens regardless of the bar diameter, as indicated in Fig. 9. The relationship between the bond and the embedment length is displayed in Fig. 11 for BFRP bars with different diameters. In the figure, the maximum bond stresses of all the tested specimens were indicated for all the different embedment lengths. It was observed from the figure that specimens possessing a $4 d_{b}$ embedment length have higher bond stress than those with $8 \mathrm{db}$ and $12 d_{b}$ embedment lengths. For instance, for an $8 \mathrm{~mm}$ diameter bar, as the embedment length was increased to $8 d_{b}$ and $12 d_{b}$ from $4 d_{b}$, the bond strength decreased by 15.6 and $25.5 \%$,respectively. Moreover, for a $10 \mathrm{~mm}$ bar diameter, as the length was increased to $8 d_{b}$ and $12 d_{b}$, the bond strength reductions were $24.7 \%$ and $37.4 \%$, respectively, while decreases in the bond strength were 31 and $45 \%$ for a $12 \mathrm{~mm}$ bar diameter as the length was increased to $8 d_{b}$ and $12 d_{b}$, respectively. These results were attributed to two failure types of the specimens. The specimens possessing larger embedment lengths have splitting failure that leads to failure of samples before the development of the full bond strength, which is associated with a nonlinear bond stress distribution causing the lower bond strength values. A similar performance was observed in the research of Maranan et al. [24] as the embed-

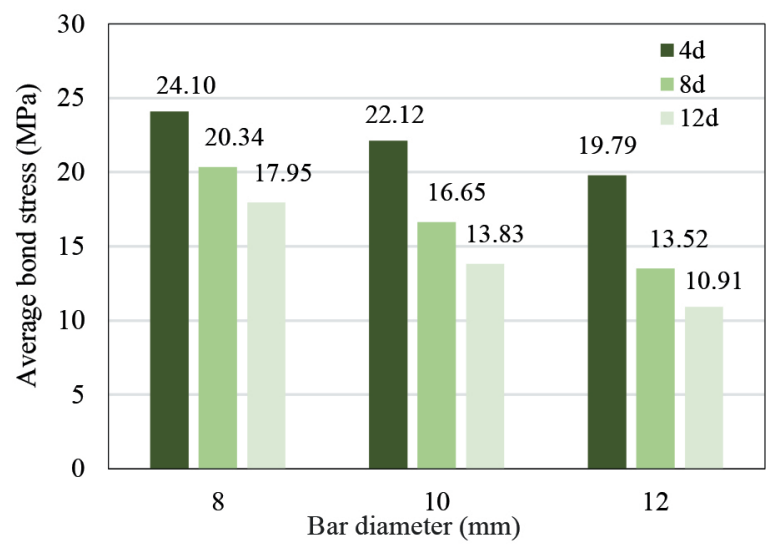

Fig. 11 Effect of embedment length on average bond strength 
ment length increased. Different studies on GFRP-reinforced OC proposed the nonlinear bond distribution as the only possible explanation for the decrease in the average bond strength [13, 32, 37]. On the other hand, it was indicated that an increase in embedment length increased the perimeter area and, therefore, led to a reduction in bond strength [24].

\subsubsection{Effect of concrete cover}

Cover values of 20,40 , and $70 \mathrm{~mm}$ with bar diameter of $10 \mathrm{~mm}$ were considered to determine effect of the GC cover. The curves of bond stress-slip for specimens possessing different concrete covers were illustrated in Fig. 12. As the concrete cover increased from $20 \mathrm{~mm}$ to $70 \mathrm{~mm}$, the curves became steeper, and the bond strength increased. For concrete cover values of 40 and $20 \mathrm{~mm}$, the ultimate bond stresses were $12.9 \mathrm{MPa}$ and 9.8 $\mathrm{MPa}$, respectively. Bond strength of the specimens, whose concrete cover was $70 \mathrm{~mm}$, was $16.7 \mathrm{MPa}$, which indicated improvement as the amounts of $71.4 \%$ and $29.3 \%$ as compared to specimens whose concrete covers were 20 and $40 \mathrm{~mm}$, respectively. The specimens possessing small concrete covers, such as 20 and $40 \mathrm{~mm}$, failed abruptly due to splitting of the concrete as shown in Fig. 8, while those with $70 \mathrm{~mm}$ covers failed due to pullout. This observation may be attributed to an adequate concrete cover of the BFRP bar which increases the bearing force. Therefore, it leads to the higher bond strength with GC and decreases the formation of cracks in the concrete that surrounds the bars, and as a result, prevents the splitting failure. As the concrete cover increased, Veljkovic et al. [38] observed a similar behavior for ordinary concrete cement. For the bars kept close to the edge, not only was the bond stress decreased (compared to the centric placed bar), but the maximum bond stress was also attained at a lesser slip of the reinforcement, as shown in Fig. 12.

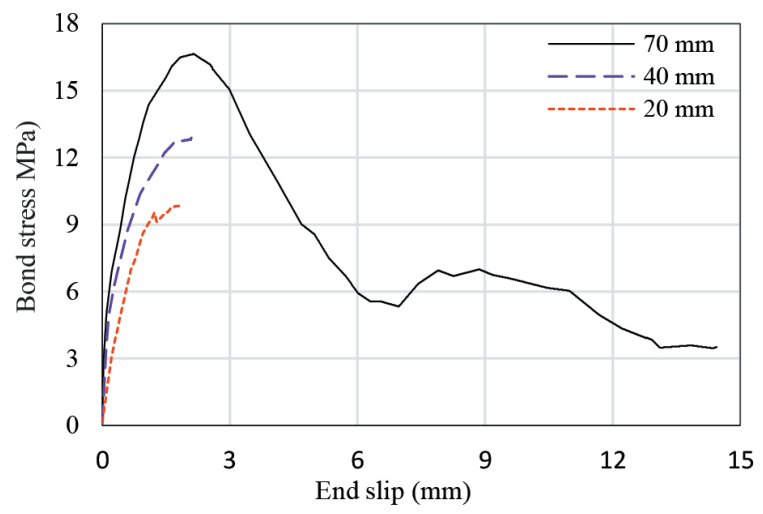

Fig. 12 Comparisons on Bond stress-slip curves for different concrete covers

\subsubsection{Effect of concrete strength}

The BFRP bar, possessing $10 \mathrm{~mm}$ diameter and embedment length of $8 \mathrm{db}$, was used to evaluate the bond stressslip behavior of GC with respect to compressive strength, as shown in Fig. 13. According to this figure an increase in the compressive strength improved the bond stress, while the slip decreased. With an increase of the concrete strength from 21.7 to $34.4 \mathrm{MPa}$ for GC/21.7/70-BR/10/8d and $\mathrm{GC} / 34.4 / 70-\mathrm{BR} / 10 / 8 \mathrm{~d}$ specimens, the optimum average bond stress also increased by $11.8 \%$. On the other hand, the corresponding slip value reduced by $13.8 \%$, as the concrete's strength increased by $36.8 \%$. The test results obtained by Baena et al. [14], who examined the bond behavior of the FRP bars in OC, explained that bond strength between FRP bars and the concrete increased as the concrete strength increased. This observation was attributed to increase in the resistance of FRP-concrete interface caused by the increase in the compressive strength of the concrete. Furthermore, increase in the concrete's tensile strength may delay formation of cracks inside the concrete and thus increased bond stress. It was observed that the higher compressive strength (34.4 $\mathrm{MPa})$ provided more crushing resistance than the lower compressive strength $(21.7 \mathrm{MPa})$ in the ribs.

\subsubsection{Effect of various surface treatment}

Effect of the bar surface on bond strength is a complicated phenomenon, since the bar can possess different surface configurations. However, no standard configuration has been provided, as in the case of steel reinforcement. Various surface configurations result in different bond behavior [16]. In this part, the FRP bars, used in the study, can be grouped into two distinct types, such as ribbed (BCHW, and BR) and non-ribbed bars (BS).

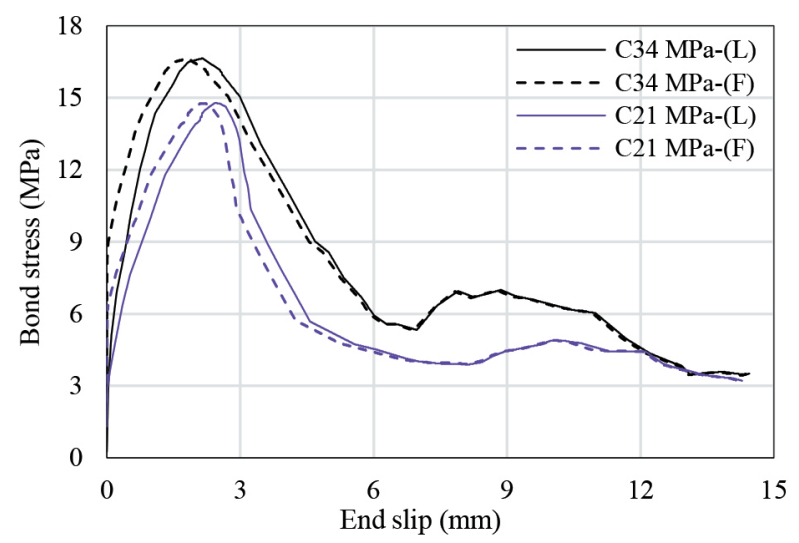

Fig. 13 Comparisons on Bond stress-slip curves for different grades of geopolymer concrete 
Cross helical wrapping, coated and ribbed bars having $10 \mathrm{~mm}$ diameter and $8 \mathrm{db}$ embedment length were all used to determine the effect of bar surface configuration on bond strength, as indicated in Fig. 14. The comparison illustrates significant difference regarding mechanisms of the bond for different surface treatments. When the bars provide a ribbed surface, the contribution of mechanical interlocking is very efficient in order to obtain high bond stresses as compared to the sand coated bars that have a small mechanical contribution. Additionally, when most of the lugs are damaged, after obtaining the highest bond stress, the softening part of ribbed bars is higher than that of sand coated bars. This result indicated that the deformation of surfaces of ribbed bars is in smaller region and so the surface still tries to develop higher bond resistance as compared to sanded bars.

Furthermore, bond stress of the FRP bars coated with sand reduces quickly upon reaching the maximum bond stress. On the other hand, the FRP bars possessing ribbed and cross helical wrapping surface configurations exhibited a more gradual decrease in bond stress. The initial phase of all the curves that correspond to chemical adhesion is coincident, and the related slips tend to be almost zero. The optimum bond stress of the specimens having cross helical wrapping surface configuration is higher as compared to the specimens having other surface configurations; however, they failed due to splitting of the concrete. On the contrary, specimens reinforced by sand coated and ribbed bars failed due to pullout failure, as shown in Fig. 7. Generally, the splitting failure produces lower bond strength than that of the pullout failure, however this case is not valid for the specimens having cross helical wrapping surface configuration. The highest bond stresses of ribbed and cross helical wrapping bars were higher as amounts of 10.3 and $19.2 \%$, respectively, compared to the sand coated

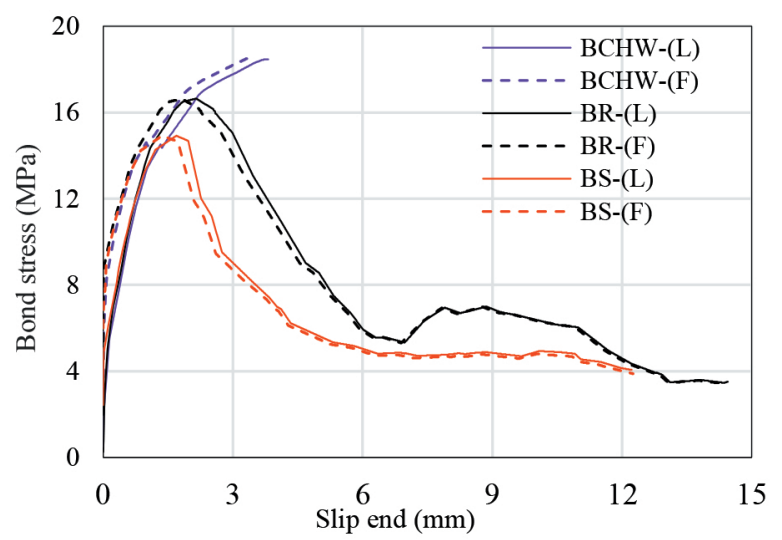

Fig. 14 Comparisons on Bond stress-slip curves for different surface condition bars. This observation can be further explained by the effect of surface geometry whereby the deformed rebars have a higher geometric ratio and the mechanical interlocking contribution, as initially demonstrated. Similar behavior for non-deformed and deformed rebars in ordinary concrete was also observed by Baena et al. [14].

\subsection{Comparison of BFRP-reinforced GC and BFRP- reinforced $\mathrm{OC}$}

The comparison of the bond behavior between OC and GC with the same parameters indicated that the specimens of BFRP-reinforced GC possessed higher average bond strength than those of OC. The bond strengths of GC and OC were compared in Fig. 15, for several bar diameters. It can be observed from the figure that bond strengths of the bars having higher diameter are smaller as compared to the bars that have smaller diameters for OC and also GC specimens. The optimum bond strength at failure for the GC possessing diameters of 8,10 , and $12 \mathrm{~mm}$ had bond strengths of $10.9,13.4$ and $12.6 \%$ more than the bond strengths achieved by the OC for the same diameters, respectively, and average increase was $12.2 \%$, as shown in Fig. 16(a). Increase in the bond strength of GC was because of a complex interfacial transition zone (ITZ) among the aggregate, bar, and the concrete. Furthermore, it was reported that sodium silicate usage led to a dense ITZ with no microstructure difference than the geopolymer matrix [22].

On the other hand, the ITZ was filled with crystalline phases comprising of ettringite and portlandite with higher porosity in OC [3]. This case can be extracted from comparison of slip values at ultimate bond stress for these two concrete types. As shown in Fig. 16(b), the slip values of BFRP bar inside the $\mathrm{GC}$ at optimum bond strengths are 4.2, 7.7, and $13.8 \%$ lower than the slip values of BFRP bars inside OC at optimum bond strengths for diameters of 8,10 and $12 \mathrm{~mm}$,

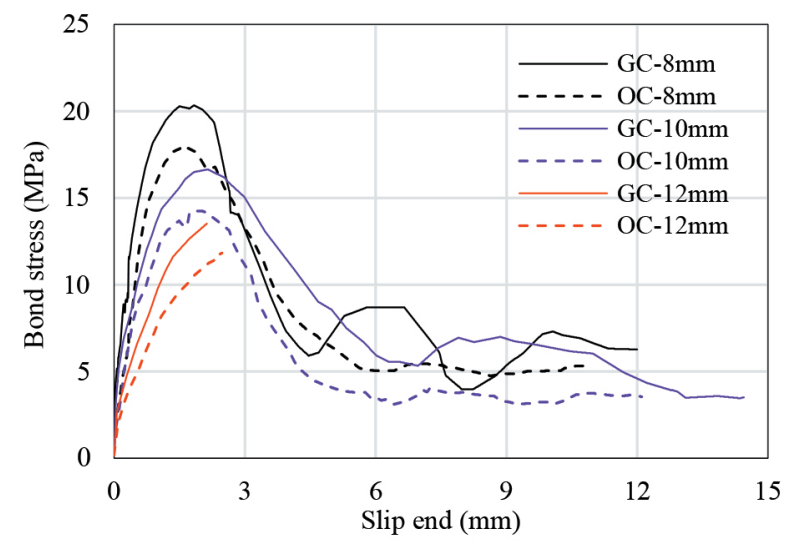

Fig. 15 Comparisons on Bond stress-slip curves for GC and OC with different bar diameter 


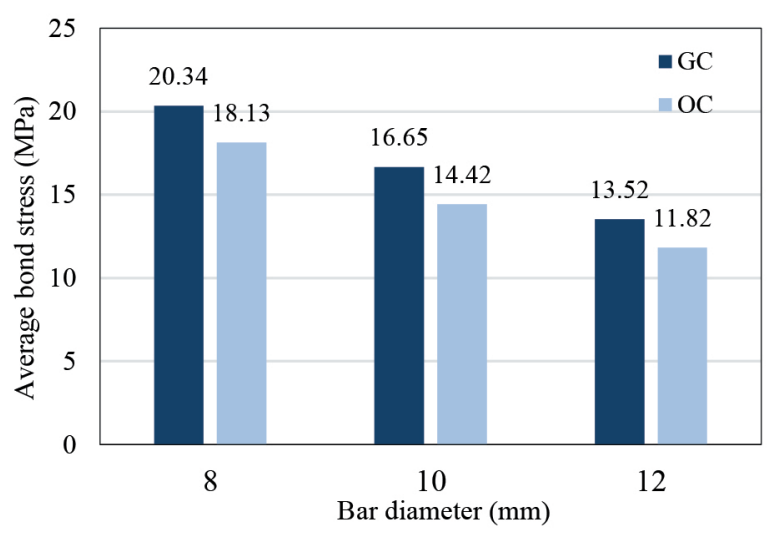

(a)

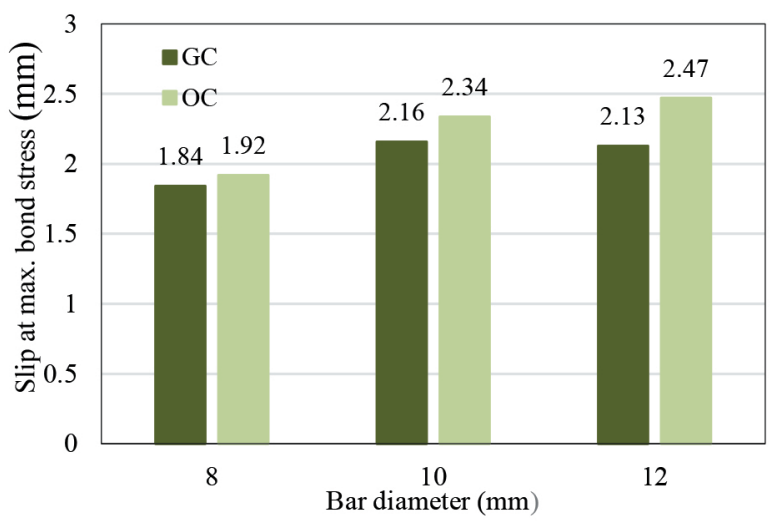

(b)

Fig. 16 Comparisons between GC and OC (a) for max. bond stress; (b) corresponding slip

respectively, and average decrease is $9.2 \%$. This outcome indicates that $\mathrm{GC}$ has higher bearing forces, chemical adhesion, and friction as compared to the OC. Better bond performance of GC than the performance of OC was also reported in several studies [24] and [25] which include tests for steel bars and GFRP bars coated with sand. Therefore, it can be concluded that the GC reinforced by BFRP bars has comparable bond strength with that of BFRP-reinforced OC and it can be an effective alternative to the BFRP-reinforced OC.

\subsection{Comparison of bond-slip specimens of BFRP / GFRP-geopolymer and steel-geopolymer}

According to Fig. 17, it can be observed that basalt and glass FRP bars showed the almost same bond behavior. Their optimum bond stresses for the $10 \mathrm{~mm}$ diameter with embedment length of $8 d_{b}$ were 16.6 and $15.2 \mathrm{MPa}$, respectively. Upon comparison, deformed steel bars with similar diameters and the same embedment length experienced bond stress equivalent to 20.1 MPa. From Fig. 17, it can be concluded that both GFRP and BFRP experienced about 76 and $83 \%$ of the steel's bond strength, respectively, but with higher slip values. This outcome results from lower elastic

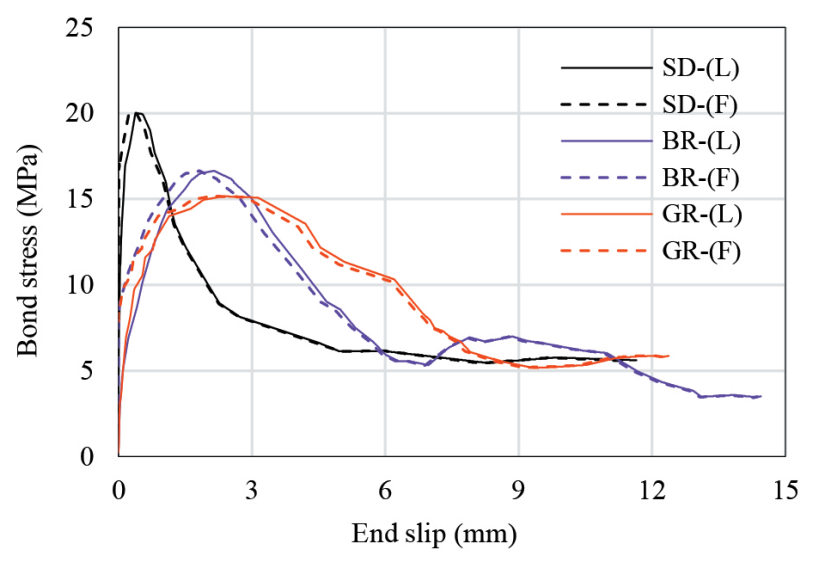

Fig. 17 Comparisons on Bond stress-slip curves for different types of bars

modulus of BFRP and GFRP bars as compared to that of steel bars (see Table 1), as also expressed by Caro et al. [39] and other different researchers [14, 37]. Besides, Maranan et al. [24] also reported higher bond strength of the ribbed steel bars. According to this study, the FRP bar reinforced specimens possess comparable bond strength as compared with steel bar reinforced specimens. Therefore, it can be deduced that ribbed FRP bars may be an efficient internal reinforcement alternative to the steel bar for the geopolymer concrete structures.

\subsection{Theoretical analysis}

Currently, various models are applied to simulate the real bond-slip behavior of FRP-reinforced concrete. The models include the Malvar, modified BPE (mBPE), BerteroEligehausen-Popov (BPE), Cosenza-Manfredi-Realfonzo (CMR), Wei (2P), Xia Li, and Gao models. As shown in Fig. 18(a), among the models, the most reliable model, which can often simulate the ascending behavior of the bond-slip curves, is the model of BPE and the CMR law proposed by Eligehausen et al. [40] and Cosenza et al. [41], respectively, as well as the $2 \mathrm{P}$ and $\mathrm{mBPE}$ models proposed by Wei et al. [9] and Cosenza et al. [42] to simulate the whole curves (ascending and descending parts) as shown in Fig. 18(b). However, the remaining models, as illustrated in Fig. 18(a), are not very suitable for BFRP bars embedded in GC because the bond-slip curves cannot be properly fitted.

\subsubsection{The BPE and mBPE model}

The BPE model was initially designed to describe the bond performance of steel bars to concrete. It consists of an ascending branch that reflects the chemical adhesion bond mechanism, a plateau phase with constant maximum bond stress, a linear downwards branch, and a final horizontal branch with constant frictional reaction. After that, 


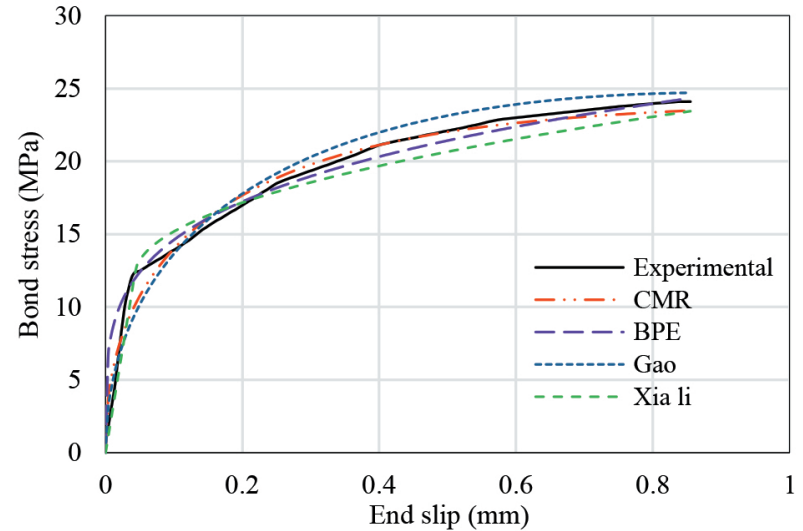

(a)

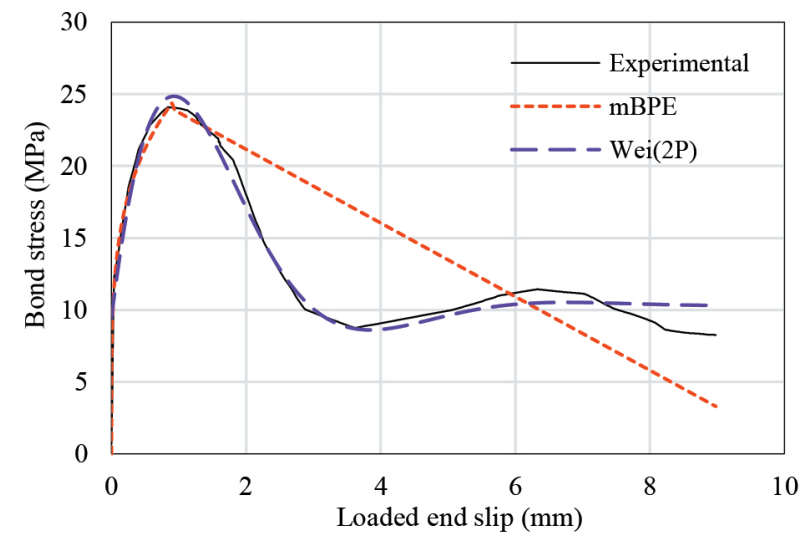

(b)

Fig. 18 Experimental data compared to different models for GC/34/70BR/8/4d specimen: (a) ascending part; (b) whole curve

the model was updated for FRP materials [42]. Because the FRP bond does not have the same apparent plateau as a steel bar, this branch in the BPE model with a constant maximum bond stress is eliminated in the BPE-modified model to properly characterize the bond stress-slip relation of FRP bars. This model also provides a whole bond stress-slip constitutive curve for FRP bars, which makes it more appropriate for FRP bars. It should be noted, however, that the impacts of varying bar diameters and FRP fiber types have not been considered in this model.

The mBPE law in its modified form is written as follows

$\frac{\tau}{\tau_{u}}=\left(\frac{s}{s_{u}}\right)^{\alpha}$ for $0 \leq s \leq s_{u}$,

$\frac{\tau}{\tau_{u}}=1-p\left(\frac{s}{s_{u}}-1\right)$ for $s_{u} \leq s \leq s_{3}$.

In the Eqs. (3) and (4), $\tau$ and $s$ are the bond stress and the slip, respectively. On the other hand, $\tau_{u}$ represents the ultimate bond stress, and $s_{u}$ is the slip at the ultimate bond stress obtained through experimental tests.

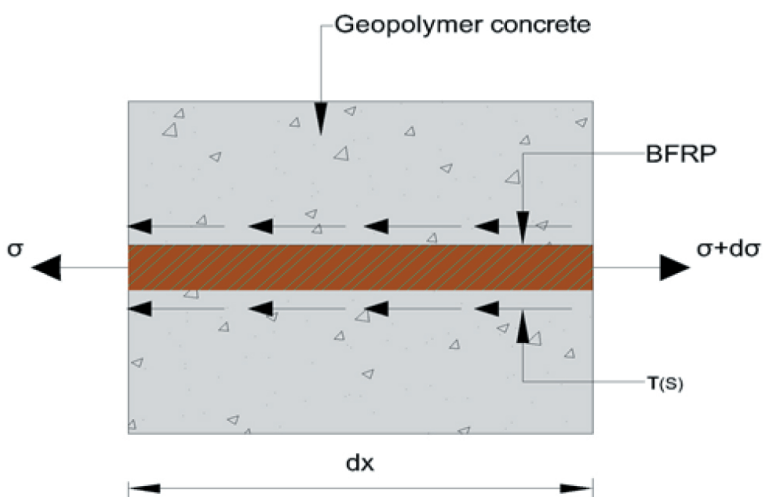

Fig. 19 Anchored BFRP infinitesimal section

To establish a numerical procedure aimed at the optimization of these parameter, Pecce et al. [43] explained that by assuming a constant bond stress distribution along the embedment length of the bar and measuring slip values at the free end, the parameters for the bond-slip constitutive laws can be determined. Because the difference between the slips at the free and loaded ends is minimal for steel bars, this approach works successfully; thus, a constant bond stress distribution is acceptable. However, because of the lower elastic modulus of FRP bars, there is a large disparity in the slips at the two ends. For each test, this yields two bond-slip curves: free-end and loaded-end curves. As a result, determining a constitutive rule for the bond strength of FRP bars is more difficult than that for steel bars.

By studying an infinitesimal piece of embedded reinforcing bar, as shown in Fig. 19, the differential equation for the problem of a reinforcing bar implanted in a concrete block may be obtained as follows if the contribution of the concrete in tension is ignored. The bond stress along the bar is defined by $\tau=\tau(s)$, where $\tau=$ shear stress acting on the bar-concrete contact surface; and $(s)=s(x)$ is a relative displacement between the concrete at position $x$ and the bar. At point $x$, the bar has a strain of $\varepsilon=\varepsilon(x) x$ and a stress of $\sigma=\sigma(\mathrm{x})$.

The controlling differential equation of the problem is Eq. (5), which is derived from the equilibrium of forces on the infinitesimal section interface, as well as the compatibility and constitutive relations of bond stress and FRP tensile stress [44].

$\frac{d^{2} s}{d x^{2}}=\frac{4}{E \cdot d_{b}} \cdot \tau(s(x))$

Where $E$ is modulus elasticity of the bar. and $x$ is a distance from the free end; Eq. (5) is valid if the FRP bar possess a linear elastic constitutive law in the longitudinal direction and the displacements of the concrete points at 
the FRP bar interface are minimal in comparison to the displacements of the bar points; i.e., the deformation of the concrete is ignored, and therefore $s(x)$ is the displacement of the FRP bar at $x$. [44].

A relation between tensile stress and slip can be determined by integrating Eq. (5). A closed-form solution to this differential equation can be found only if the development length is shorter than the embedment length of the bar, in which case the free-end slip is zero. This equation, as determined by Pecce et al. [43], is as follows:

$$
\sigma\left(s_{l}\right)=\sqrt{\frac{8 E}{d_{b}} A_{\tau}\left(s_{l}\right)}
$$

$A_{\tau}$ symbolizes the area beneath the $\tau$-s curve. Eq. (6) is only applicable if the free-end slip is zero. However, because the free-end slip for all of the samples in this current case is higher than zero, the closed-form solution can be utilized. As a result, Eq. (5) is integrated numerically with the following boundary conditions: $\sigma=\sigma_{f}^{\exp }=0 ; s=s_{f}^{\exp }$.

With these boundary conditions and use a set of assumed tentative parameter values as a starting point, $\left(s, s_{m}, \tau, \tau_{m}, \alpha\right.$ and $p$ for mBPE model) Euler's technique is used to solve Eq. (5). The theoretical values of slip and stress at the loaded end of the bar's embedment length are estimated for each loading step of the experiment. The optimal values of the bond-slip relationship parameters are determined by comparing theoretical slip and stress at the loaded end with experimental values. To optimize these parameters, Pecce et al. [43] applied the error function Eq. (7).

$$
e=\sqrt{\frac{\sum_{j=1 . n}\left(\frac{s_{l}^{t h}-s_{l}^{\exp }}{s_{l}^{\exp }}\right)+\left(\frac{\sigma_{l}^{t h}-\sigma_{l}^{\exp }}{\sigma_{l}^{\exp }}\right)}{n}}
$$

$s_{l}^{\text {exp }}, s_{l}^{\text {th }}, \sigma_{l}^{\text {exp }}$ and $\sigma_{l}^{\text {th }}$ represent the experimental and theoretical slip and stress at the loaded end, respectively, and $\mathrm{n}$ represents the number of loading steps, i.e., the number of data points from the experiment. All of the specimens are subjected to the preceding procedure. Table 6 summarizes the parameter mean values obtained for two identical specimens for each set with the mean design values of the bond strength and even corresponding slippage.

\subsubsection{CMR model}

To overcome the shortcomings of Malvar's model, Cosenza et al. [41] presented the CMR model to better express the ascending behavior in the first phase of the bond stressslip curve for FRP bars to concrete in the following form: $\tau=\tau_{u} \cdot\left(1-e^{\left(-s / s_{r}\right)}\right)^{\beta}$

In the Eq. (8), $\tau$ and $s$ are the bond stress and the slip, respectively. $\tau_{u}$ represents the ultimate bond stress obtained through experimental tests. Moreover, $s_{r}$ and $\beta$ are unknown parameters and are obtained through curve fitting of the experimental results.

The various 38 pullout specimens were modelled through the use of the CMR model that adopted the curve fitting method to determine the values of $s_{r}$ and $\beta$. The mean values of $s_{r}$ and $\beta$ were calculated to calibrate the model parameters. Table 6 tabulates the $s_{r}$ and $\beta$ average values obtained for two identical specimens for each set with the mean design values of the bond strength and even corresponding slippage. As illustrated in Table 6, various parameters are obtained from various specimens. Because of these variances, the average bond-slip law for all specimens can only provide broad guidance on the bond slip behavior of the BFRP bars. Therefore, instead of using the mean value for all specimens, the average calibrated parameters for each pair of specimens in the same set are employed to depict the ascending branches.

\subsubsection{Wei (2P) model}

Both the mBPE and CMR models are capable of accurately simulating the initial ascending part of the bond stressslip curve. The two models, however, have some shortcomings. On the one hand, the intersection of the ascending and descending parts in the mBPE model is not smooth; on the other hand, the descending part is a straight line, which contradicts the test results. The descending and residual stress parts of the bond stress-slip curve are not represented by the CMR model. As a result, to more properly represent the bond stress-slip constitutive model, Wei suggested the $2 \mathrm{P}$ model based on the bond mechanism as well as the bond properties. Eq. (9) is used to express this, where $b, \eta, \omega, \varphi$, and $c$ are the parameters attained by curve fitting.

$\tau=b e^{-\eta s} \cos (\omega s+\varphi)+c$

\subsubsection{Comparisons between the 2P, mBPE and CMR models}

Comparisons between the 2P, mBPE, and CMR models were performed to estimate the efficiency of the models. Meanwhile, the root mean square error (RMSE) of the bond stress was used, as expressed in Eq. (10), where $\tau_{\text {exp }}$ represents the experimental bond stress, $\tau_{f i t}$ represents the fitting bond stress, and $n$ represents the number of data 
points. Table 7 summarizes the RMSE of the $2 \mathrm{P}, \mathrm{mBPE}$, and CMR models. The CMR model provided the best fitting effect for the first ascending part of the bond stressslip curve. The 2P model had a better fitting effect than the mBPE model over the entire bond stress-slip curve.

$\operatorname{RMSE}=\sqrt{\frac{\sum\left(\tau_{\text {exp }}-\tau_{f i t}\right)^{2}}{n}}$

Fig. 18(a), (b) and Fig. 20(a), (b) show the comparison of the curves of the analytical model and experimental results for the $\mathrm{GC} / 34 / 70-\mathrm{BR} / 8 / 4 \mathrm{~d}$ and $\mathrm{GC} / 34 / 70-\mathrm{BR} / 10 / 8 \mathrm{~d}$ specimen as an example. It is observed that all the $\mathrm{mBPE}, \mathrm{CMR}$ and $2 \mathrm{P}$ models agreed well with the tested bond stressslip curves. For the ascending branch, it is seen that the CMR model presents a better correlation with the experimental data compared to the mBPE model for the ascending part, and this is true for all the specimens as shown in Fig. 20(a) and Table 7 in which the RMSE for the CMR model is smaller than that for the mBPE model. There is associated with the fact that the mBPE model was specifically developed for steel bars with no slippage until high levels of loading that were very close to the peak load, which indicated a high adhesion of steel reinforcement to concrete. In this research, the applied BFRP possesses lower adhesion stresses, unlike conventional steel reinforcements. This led to conservative bond strength values as the curve approached the ultimate stress as well as overestimated bond strength values at the first loading levels of the ascending branch in the case of the MBPE model. The mBPE model presented a better correlation with the pullout specimens, which seem to possess high adhesion stress, as shown in Fig. 20(b) for the deformed steel bar specimen.

Furthermore, Fig. 20(b) and Table 7 show that there is a better agreement between the experimental results and the $2 \mathrm{P}$ model for the whole curves, and the RMSE for the $2 \mathrm{P}$ model is smaller than that of the mBPE model. Therefore, these equations can be applied in carrying out numerical evaluation on the GC and BFRP bar bonds.

As illustrated in Table 6 many different parameters are obtained from many various specimens. However, new model of bond-slip relationships can be proposed but because of these variances in using many variables and limiting number of specimens, taking the average calibrated parameters for all specimens or collecting all of the variables in one analytical model can only provide broad guidance on the BFRP bar's bond slip behavior, Therefore,

Table 6 Proposed Design Values for the Parameters of the mBPE, CMR and 2P Models

\begin{tabular}{|c|c|c|c|c|c|c|c|c|c|c|c|c|c|c|c|}
\hline \multirow[b]{2}{*}{ specimens } & \multicolumn{4}{|c|}{ mBPE } & \multicolumn{4}{|c|}{ CMR } & \multicolumn{7}{|c|}{$2 \mathrm{P}$} \\
\hline & $\begin{array}{c}\tau_{\max }^{a} \\
(\mathrm{MPa})\end{array}$ & $\begin{array}{c}S_{\max }^{a} \\
(\mathrm{~mm})\end{array}$ & $\alpha$ & $p$ & $\begin{array}{c}\tau_{\max }^{a} \\
(\mathrm{MPa})\end{array}$ & $\begin{array}{c}S_{\max }^{a} \\
(\mathrm{~mm})\end{array}$ & $\beta$ & $S r$ & $\begin{array}{c}\tau_{\max }^{a} \\
(\mathrm{MPa})\end{array}$ & $\begin{array}{c}S_{\max }^{a} \\
(\mathrm{~mm})\end{array}$ & $b$ & $\eta$ & $\omega$ & $\varphi$ & $c$ \\
\hline $\mathrm{GC} / 34 / 70-\mathrm{BR} / 8 / 4 \mathrm{~d}$ & 24.37 & 0.88 & 0.338 & 0.091 & 23.73 & 0.90 & 0.432 & 0.288 & 24.85 & 0.91 & 34.68 & 0.733 & -1.077 & -10.970 & 10.323 \\
\hline $\mathrm{GC} / 34 / 70-\mathrm{BR} / 10 / 4 \mathrm{~d}$ & 22.14 & 1.28 & 0.281 & 0.119 & 21.56 & 1.34 & 0.571 & 0.426 & 22.33 & 1.30 & 47.11 & 0.732 & 0.706 & -26.770 & 8.673 \\
\hline $\mathrm{GC} / 34 / 70-\mathrm{BR} / 12 / 4 \mathrm{~d}$ & 19.79 & 2.14 & 0.317 & 0.129 & 19.56 & 2.04 & 0.679 & 0.631 & 19.13 & 2.20 & 4211. & 0.630 & -0.005 & -551.0 & 6.875 \\
\hline $\mathrm{GC} / 34 / 70-\mathrm{BR} / 8 / 8 \mathrm{~d}$ & 20.34 & 1.86 & 0.314 & 0.181 & 20.06 & 1.84 & 0.907 & 0.438 & 20.43 & 1.81 & 56.44 & 0.712 & 0.589 & -26.800 & 6.536 \\
\hline $\mathrm{GC} / 34 / 70-\mathrm{BR} / 10 / 8 \mathrm{~d}$ & 16. 71 & 2.16 & 0.341 & 0.175 & 16.15 & 2.16 & 0.738 & 0.671 & 16.29 & 2.13 & -82.00 & 0.592 & 0.252 & -1.529 & 4.974 \\
\hline $\mathrm{GC} / 34 / 70-\mathrm{BR} / 12 / 8 \mathrm{~d}$ & 13.49 & 2.13 & 0.482 & - & 12.73 & 2.13 & 0.942 & 0.762 & 13.49 & 2.12 & 19.60 & 0.426 & 0.427 & -14.573 & 9.881 \\
\hline $\mathrm{GC} / 34 / 70-\mathrm{BR} / 8 / 12 \mathrm{~d}$ & 17.97 & 2.45 & 0.399 & - & 17.64 & 2.45 & 1.264 & 0.571 & 17.86 & 2.46 & -21.83 & 1.684 & -0.649 & 0.589 & 18.047 \\
\hline $\mathrm{GC} / 34 / 70-\mathrm{BR} / 10 / 12 \mathrm{~d}$ & 13.77 & 2.61 & 0.435 & - & 13.21 & 2.61 & 0.905 & 0.866 & 13.33 & 2.61 & -13.61 & 1.184 & 0.000 & -0.001 & 13.954 \\
\hline $\mathrm{GC} / 34 / 70-\mathrm{BR} / 12 / 12 \mathrm{~d}$ & 10.91 & 2.02 & 0.556 & - & 10.54 & 2.02 & 1.746 & 0.515 & 10.98 & 2.05 & -74.18 & 2.048 & -0.210 & 13.978 & 11.631 \\
\hline $\mathrm{GC} / 34 / 70-\mathrm{BS} / 10 / 8 \mathrm{~d}$ & 14.92 & 1.69 & 0,308 & 0.159 & 12.32 & 1.71 & 0.533 & 0.652 & 14.53 & 1.69 & -17.94 & 0.005 & 0.057 & 1.331 & 4.261 \\
\hline $\mathrm{GC} / 34 / 70-\mathrm{BCHW} / 10 / 8 \mathrm{~d}$ & 18.47 & 3.82 & 0.393 & - & 10.04 & 3.82 & 0.632 & 1.151 & 18.18 & 3.85 & -15.85 & 1.025 & 0.000 & 0.184 & 18.497 \\
\hline $\mathrm{GC} / 34 / 70-\mathrm{GR} / 10 / 8 \mathrm{~d}$ & 15.26 & 2.34 & 0.242 & 0.194 & 14.94 & 2.37 & 0.586 & 0.613 & 15.60 & 2.37 & -23.85 & 0.286 & -0.380 & -1.552 & 6.257 \\
\hline $\mathrm{GC} / 34 / 70-\mathrm{SD} / 10 / 8 \mathrm{~d}$ & 18.65 & 0.40 & 0.242 & 0.037 & 18.43 & 0.40 & 0.414 & 0.15 & 19.48 & 0.45 & -6851 & 1.683 & -0.008 & -1.571 & 6.000 \\
\hline $\mathrm{GC} / 34 / 20-\mathrm{BR} / 10 / 8 \mathrm{~d}$ & 9.84 & 1.85 & 0.422 & - & 9.66 & 1.85 & 1.374 & 0.432 & 9.76 & 1.87 & -9.00 & 1.345 & -1.251 & 0.052 & 9.228 \\
\hline $\mathrm{GC} / 34 / 40-\mathrm{BR} / 10 / 8 \mathrm{~d}$ & 12.93 & 2.09 & 0.330 & - & 12.52 & 2.20 & 0.712 & 0.643 & 12.84 & 2.20 & -17.87 & 1.600 & 0.000 & -5.416 & 13.243 \\
\hline $\mathrm{GC} / 21.7 / 70-\mathrm{BR} / 10 / 8 \mathrm{~d}$ & 14.79 & 2.84 & 0.413 & 0.233 & 13.89 & 2.48 & 0.649 & 1.013 & 13.62 & 2.50 & -25.08 & 0.425 & 0.578 & -36.270 & 4.473 \\
\hline $\mathrm{OC} / 34 / 70-\mathrm{BR} / 8 / 8 \mathrm{~d}$ & 17.91 & 1.69 & 0.450 & 0.186 & 17.59 & 1.67 & 1.649 & 0.369 & 17.93 & 1.60 & 45.16 & 0.586 & 0.573 & -39.400 & 5.361 \\
\hline $\mathrm{OC} / 34 / 70-\mathrm{BR} / 10 / 8 \mathrm{~d}$ & 14.25 & 1.93 & 0.410 & 0.203 & 13.82 & 1.89 & 1.019 & 0.539 & 14.16 & 2.10 & 30.68 & 0.505 & 0.610 & -33.100 & 3.795 \\
\hline $\mathrm{OC} / 34 / 70-\mathrm{BR} / 12 / 8 \mathrm{~d}$ & 11.82 & 2.02 & 0.511 & - & 11.09 & 2.46 & 1.012 & 0.887 & 11.74 & 2.50 & -25.941 & 0.588 & -0.092 & -1.071 & 13.375 \\
\hline
\end{tabular}

Note: $\max =$ maximum bond stress; $a=$ average for the two identical specimens. ; $S_{\max }=$ slip corresponding to maximum bond stress 
Table 7 RMSE of the 2P, mBPE and CMR models

\begin{tabular}{|c|c|c|c|c|}
\hline \multirow[t]{2}{*}{ specimens } & \multicolumn{2}{|c|}{$\begin{array}{c}\text { First ascending part } \\
\text { of curve }\end{array}$} & \multicolumn{2}{|c|}{ Whole curve of } \\
\hline & CMR & mBPE & $2 \mathrm{P}$ & $\mathrm{mBPE}$ \\
\hline $\mathrm{GC} / 34 / 70-\mathrm{BR} / 8 / 4 \mathrm{~d}$ & 0.602 & 0.282 & 0.892 & 1.432 \\
\hline $\mathrm{GC} / 34 / 70-\mathrm{BR} / 10 / 4 \mathrm{~d}$ & 0.508 & 1.002 & 0.755 & 4.022 \\
\hline $\mathrm{GC} / 34 / 70-\mathrm{BR} / 12 / 4 \mathrm{~d}$ & 0.445 & 0.929 & 0.499 & 3.028 \\
\hline $\mathrm{GC} / 34 / 70-\mathrm{BR} / 8 / 8 \mathrm{~d}$ & 0.572 & 1.526 & 1.356 & 4.418 \\
\hline $\mathrm{GC} / 34 / 70-\mathrm{BR} / 10 / 8 \mathrm{~d}$ & 0.503 & 0.797 & 0.980 & 2.594 \\
\hline $\mathrm{GC} / 34 / 70-\mathrm{BR} / 12 / 8 \mathrm{~d}$ & 0.309 & 0.417 & 0.200 & - \\
\hline $\mathrm{GC} / 34 / 70-\mathrm{BR} / 8 / 12 \mathrm{~d}$ & 0.184 & 1.445 & 0.189 & - \\
\hline $\mathrm{GC} / 34 / 70-\mathrm{BR} / 10 / 12 \mathrm{~d}$ & 0.271 & 0.372 & 0.420 & - \\
\hline $\mathrm{GC} / 34 / 70-\mathrm{BR} / 12 / 12 \mathrm{~d}$ & 0.762 & 0.241 & 0.123 & - \\
\hline $\mathrm{GC} / 34 / 70-\mathrm{BS} / 10 / 8 \mathrm{~d}$ & 0.586 & 0.572 & 11.38 & 2.947 \\
\hline GC/34/70-BCHW/10/8d & 0.273 & 0.895 & 0.273 & - \\
\hline $\mathrm{GC} / 34 / 70-\mathrm{GR} / 10 / 8 \mathrm{~d}$ & 0.178 & 0.913 & 0.544 & 1.257 \\
\hline $\mathrm{GC} / 34 / 70-\mathrm{SD} / 10 / 8 \mathrm{~d}$ & 0.392 & 0.334 & 0.572 & 1.597 \\
\hline $\mathrm{GC} / 34 / 20-\mathrm{BR} / 10 / 8 \mathrm{~d}$ & 0.230 & 0.803 & 0.119 & - \\
\hline $\mathrm{GC} / 34 / 40-\mathrm{BR} / 10 / 8 \mathrm{~d}$ & 0.288 & 0.672 & 1.347 & - \\
\hline $\mathrm{GC} / 21.7 / 70-\mathrm{BR} / 10 / 8 \mathrm{~d}$ & 0.610 & 0.317 & 0.775 & 3.400 \\
\hline $\mathrm{OC} / 34 / 70-\mathrm{BR} / 8 / 8 \mathrm{~d}$ & 0.554 & 1.563 & 0.587 & 3.064 \\
\hline $\mathrm{OC} / 34 / 70-\mathrm{BR} / 10 / 8 \mathrm{~d}$ & 0.325 & 0.838 & 0.500 & 3.071 \\
\hline $\mathrm{OC} / 34 / 70-\mathrm{BR} / 12 / 8 \mathrm{~d}$ & 0.165 & 0.328 & 0.127 & - \\
\hline
\end{tabular}

Note: $\max =$ maximum bond stress; $a$ = average for the two identical specimens; $S_{\max }=$ slip co rresponding to maximum bond stress

instead of using the mean value for all specimens, the average calibrated parameters for each pair specimens in same category are employed to depict the ascending branches or whole curves for the purpose of comparison. The analytical models might also be applied in specimens that failed due to concrete splitting since specimens with the same diameter have the same bond-slip linear stiffness behavior. However, the maximum bond stress that exists between the BFRP bars and the GC for specimens possessing longer embedment lengths may be minimal due to the splitting failure of the concrete. However, this is a conservative value that can be applied in comprehending the structural behavior at the serviceability state level. The outcomes obtained in this research are not adequate in evaluating the maximum bond stress in which concrete splitting will begin to occur, that is, the upper limit for its usage for this failure type. Therefore, further investigation is required, which is far beyond the scope of this paper. Instead of, this section in this study mostly focusing on the Comparisons between the existing models to demonstrate the best bond stress-slip model for FRP bars and geopolymer concrete among the others.

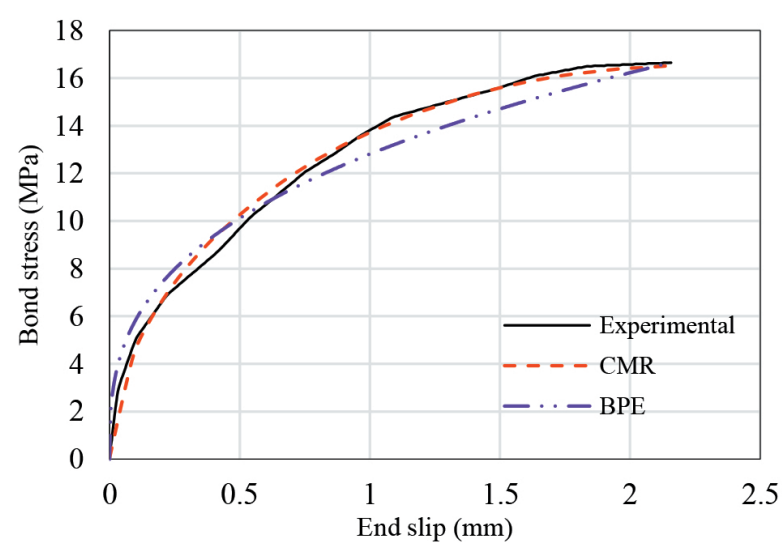

(a)

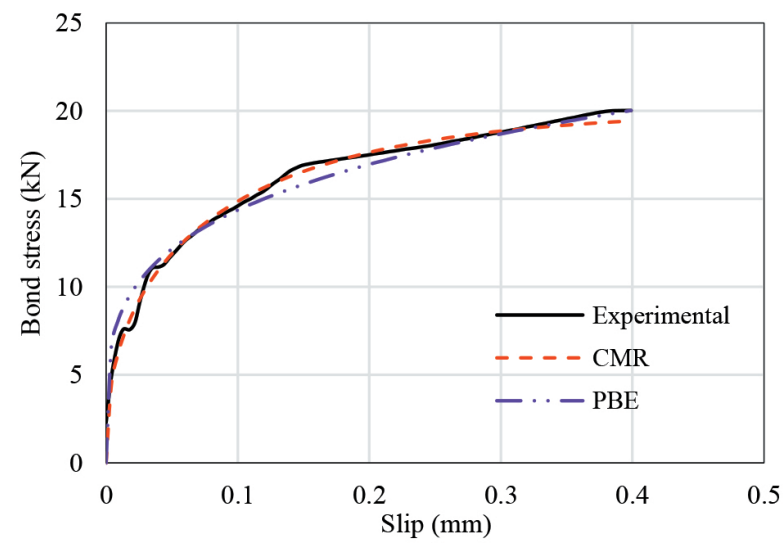

(b)

Fig. 20 Experimental data compared to BPE and CMR models for: (a) BFRP; (b) Steel bar

\section{Conclusions}

This study examined the bond-slip behavior between geopolymer concrete and FRP reinforcing bars via a comprehensive experimental study in detail. The pullout tests were conducted to evaluate the effects of embedment length, compressive strength, cover thickness, bar diameters, and the surface configuration of FRP bars on bond-slip behavior between geopolymer concrete and BFRP bars. Besides, the bond-slip curves for the average bond stress, bond failure mode, as well as the slip at the loaded and free ends were also examined for all the specimens. Moreover, comparisons of the bond characteristics between various types of FRP rebar and deformed steel rebar and ordinary concrete were also performed. Then, the analytical models were calibrated to describe the bond-slip relationships.

From the obtained results and the analysis, the following conclusions can be drawn.

1. The specimens that have shorter embedment lengths failed as a result of bar pullout, whereas the ones having a longer length failed as a result of concrete 
splitting. An increase in diameter made the concrete splitting failure more dominant for specimens having higher embedment lengths.

2. The bond strength between geopolymer concrete and BFRP bar reduced as the bar diameter increased. Bond strength of the specimen having diameters of $8 \mathrm{~mm}$ was $16.45 \%$ higher than the strength of the specimen having diameter of $10 \mathrm{~mm}$. This result was because of the combined effect of the non-uniform stress distribution along the bar with the shear lag in cross-section of the bar, the size, and Poisson effects.

3. Moreover, an increase in the embedded length decreased the average bond stress. Increase of the length from $4 \mathrm{db}$ to $8 \mathrm{db}$ reduced the bond's stress by $15.6 \%$ and $24.7 \%$ for the specimens having diameters of 8 and $10 \mathrm{~mm}$, respectively.

4. Additionally, bond strength between FRP bars and geopolymer concrete increased as the concrete cover increased. Therefore, increasing the cover from 20 and $40 \mathrm{~mm}$ to about $70 \mathrm{~mm}$ increased bond strengths $71.4 \%$ and $29.3 \%$, respectively. Moreover, the concrete splitting failure occurred in the specimens whose concrete cover was smaller, while the specimens having higher concrete cover failed due to pullout.

5. The compressive strength affected the bond stress of BFRP-reinforced GC significantly. An increase in compressive strength from 21.7 to about 34.4MPa led to an $11.8 \%$ increase in maximum bond stress and $13.76 \%$ decrease in the corresponding slip value.

\section{References}

[1] Davidovits, J. "Geopolymer cement" [pdf] Geopolymer Institute Library, Saint-Quentin, France, Technical Paper 21, 2013. Available at: https://www.geopolymer.org/wp-content/uploads/ GPCement2013.pdf

[2] Coccia, S., Imperatore, S., Rinaldi, Z. "Influence of corrosion on the bond strength of steel rebars in concrete", Materials and Structures, 49, pp. 537-551, 2016. https://doi.org/10.1617/s11527-014-0518-x

[3] Duxson, P., Provis, J. L., Lukey, G. C., Van Deventer, J. S. J. "The role of inorganic polymer technology in the development of 'green concrete"', Cement and Concrete Research, 37, pp. 1590-1597, 2007.

https://doi.org/10.1016/j.cemconres.2007.08.018

[4] Davidovits, J. "Geopolymer Chemistry and Applications", 4th ed., Institute Gèopolymère, Saint-Quentin, France, 2015.

[5] Neupane, K. "Fly ash and GGBFS based powder-activated geopolymer binders: A viable sustainable alternative of portland cement in concrete industry", Mechanics of Materials, 103, pp. 110-122, 2016. https://oi.org/10.1016/j.mechmat.2016.09.012
6. Additionally, no noticeable difference was observed between the bond strengths of BFRP and GFRP bars.

7. Besides, the bond's performance depends on surface conditions in terms of bond strength and bond mechanisms. For the ribbed FRP bars, the mechanical interlocking contribution is very efficient, enabling the achievement of a $19.22 \%$ higher peak bond stress than the sand coated rebars. In the case of sand coated FRP rebars, the bond is attributed to friction and chemical adhesion from the sand on the surface. Therefore, bond stress drops abruptly after the loss of the chemical bond. On the other hand, the FRP rebars containing ribbed and cross helical wrapping surface configuration experience a more gradual decrease of the bond stress.

8. The bond-slip behavior of the ribbed BFRP-reinforced $\mathrm{GC}$ is comparable as that of the $\mathrm{OC}$ reinforced by FRP or steel because it shows similar phases comprising of the linear stage, nonlinear behavior, and softening whenever pullout failure occurs.

9. Moreover, the ribbed BFRP-reinforced GC possesses a better bond performance as compared to that of the OC. This is illustrated by the increase in bond strengths of BFRP-reinforced concrete specimens with lower corresponding slip. Average bond strength was $12.2 \%$ higher and the corresponding slip value was $9.22 \%$ lower than those values of $\mathrm{OC}$ as results of several specimens were taken into account.

[6] Nanni, A., De Luca, A., Zadeh, H. J. "Reinforced Concrete with FRP Bars Mechanics and Design", CRC Press, Boca Raton, FL, USA, 2019.

[7] Elgabbas, F., Ahmed, E. A., Benmokrane, B. "Physical and mechanical characteristics of new basalt-FRP bars for reinforcing concrete structures", Construction and Building Materials, 95, pp. 623-635, 2015. https://doi.org/10.1016/j.conbuildmat.2015.07.036

[8] El Refai, A., Ammar, M.-A., Masmoudi, R. "Bond performance of basalt fiber-reinforced polymer bars to concrete", Journal of Composites for Construction, 19(3), Article number: 4014050, 2015. https://doi.org/10.1061/(asce)cc.1943-5614.0000487

[9] Wei, W., Liu, F., Xiong, Z., Lu, Z., Li, L. "Bond performance between fibre-reinforced polymer bars and concrete under pull-out tests", Construction and Building Materials, 227, Article number: 116803, 2019. https://doi.org/10.1016/j.conbuildmat.2019.116803

[10] Aiello, M. A., Leone, M., Pecce, M. "Bond performances of FRP rebars-reinforced concrete", Journal of Materials in Civil Engineering, 19(3), pp. 205-213, 2007.

https://doi.org/10.1061/(ASCE)0899-1561(2007)19:3(205) 
[11] Lin, X, Zhang, Y. X. "Evaluation of bond stress-slip models for FRP reinforcing bars in concrete", Composite Structures, 107, pp. 131141, 2014.

https://doi.org/10.1016/j.compstruct.2013.07.037

[12] De Lorenzis, L., Rizzo, A., La Tegola, A. "A modified pull-out test for bond of near-surface mounted FRP rods in concrete", Composites Part B: Engineering, 33, pp. 589-603, 2002.

https://doi.org/10.1016/S1359-8368(02)00052-5

[13] Arias, J. P. M., Vazquez, A., Escobar, M. M. "Use of sand coating to improve bonding between GFRP bars and concrete", Journal of Composite Materials, 46(18), pp. 2271-2278, 2012. https://doi.org/10.1177/0021998311431994

[14] Baena, M., Torres, L., Turon, A., Barris, C. "Experimental study of bond behaviour between concrete and FRP bars using a pull-out test", Composites Part B: Engineering, 40, pp. 784-797, 2009. https://doi.org/10.1016/j.compositesb.2009.07.003

[15] Yan, F., Lin, Z., Yang, M. "Bond mechanism and bond strength of GFRP bars to concrete: A review", Composites Part B: Engineering, 98, pp. 56-69, 2016. https://doi.org/10.1016/j.compositesb.2016.04.068

[16] Meda, A., Rinaldi, Z., Spagnuolo, S. "Experimental investigation on the behaviour of concrete ties reinforced with GFRP bars", Composite Structures, 254, Article number: 112805, 2020. https://doi.org/10.1016/j.compstruct.2020.112805

[17] Solyom, S., Balázs, G. L. "Bond of FRP bars with different surface characteristics", Construction and Building Materials, 264, Article number: 119839, 2020.

https://doi.org/10.1016/j.conbuildmat.2020.119839

[18] Vilanova, I., Baena, M., Torres, L., Barris, C. "Experimental study of bond-slip of GFRP bars in concrete under sustained loads", Composites Part B: Engineering, 74, pp. 42-52, 2015. https://doi.org/10.1016/j.compositesb.2015.01.006

[19] Mosley, C. P., Tureyen, A. K., Frosch, R. J. "Bond strength of nonmetallic reinforcing bars", ACI Structural Journal, 105(5), pp. 634-642, 2008.

[20] Solyom, S., Balázs, G. L. "Bond of FRP bars in air-entrained concrete: Experimental and statistical study", Construction and Building Materials, 300, Article number: 124193, 2021. https://doi.org/10.1016/j.conbuildmat.2021.124193

[21] Sofi, M., Van Deventer, J. S. J., Mendis, P. A., Lukey, G. C. "Bond performance of reinforcing bars in inorganic polymer concrete (IPC)", Journal of Materials Science, 42, pp. 3107-3116, 2007. https://doi.org/10.1007/s10853-006-0534-5

[22] Sarker, P. K. "Bond strength of reinforcing steel embedded in fly ash-based geopolymer concrete", Materials and Structures, 44, pp. 1021-1030, 2011. https://doi.org/10.1617/s11527-010-968

[23] Selby, D. R. "An investigation into the bond of steel reinforcement in geopolymer and ordinary portland cement concrete", UNSW Canberra ADFA Journal Undergraduate Engineering Research, 4, 2012.

[24] Maranan, G., Manalo, A., Karunasena, K., Benmokrane, B. "Bond Stress-Slip Behavior: Case of GFRP Bars in Geopolymer Concrete", Journal of Materials in Civil Engineering, 27, Article number: 04014116, 2015.

https://doi.org/10.1061/(asce)mt.1943-5533.0001046
[25] Tekle, B. H., Khennane, A., Kayali, O. "Bond Properties of SandCoated GFRP Bars with Fly Ash-Based Geopolymer Concrete", Journal of Composites for Construction, 20, Article number: 4016025, 2016. https://doi.org/10.1061/(asce)cc.1943-5614.0000685

[26] ASTM "ASTM C989-05 Standard Specification for Ground Granulated Blast-Furnace Slag for Use in Concrete and Mortars", ASTM International, West Conshohocken, PA, USA, 2005.

[27] ASTM "ASTM C618 Standard Specification for Coal Fly Ash and Raw or Calcined Natural Pozzolan for Use", ASTM International, West Conshohocken, PA, USA, 2010.

[28] ASTM "ASTM C127 Standard Test Method for Relative Density (Specific Gravity) and Absorption of Coarse Aggregate", ASTM International, West Conshohocken, PA, USA, 2015.

[29] Olivia, M., Nikraz, H. "Properties of fly ash geopolymer concrete designed by Taguchi method", Materials \& Design (1980-2015), 36, pp. 191-198, 2012. https://doi.org/10.1016/j.matdes.2011.10.036

[30] ACI "ACI 440.3R-04 Guide Test Methods for Fiber-Reinforced Polymers (FRPs) for Reinforcing or Strengthening Concrete Structures", American Concrete Institute, Farmington Hills, MI, USA 2004.

[31] CSA "CSA-S806-12 Design and construction of building structures with fibre-reinforced polymers", Canadian Standards Association, Mississauga, ON, Canada, 2012.

[32] Okelo, R., Yuan, R. L. "Bond strength of fiber reinforced polymer rebars in normal strength concrete", Journal of Composites for Construction, 9(3), pp. 203-213, 2005. https://doi.org/10.1061/(ASCE)1090-0268(2005)9:3(203)

[33] Zhang, B., Benmokrane, B., Chennouf, A. "Prediction of tensile capacity of bond anchorages for FRP tendons", Journal of Composites for Construction, 4(2), pp 39-47, 2000. https://doi.org/10.1061/(ASCE)1090-0268(2000)4:2(39)

[34] Lee, J.-Y., Kim, T.-Y., Kim, T.-J., Yi, C.-K., Park, J.-S., You, Y.-C., Park, Y.-H. "Interfacial bond strength of glass fiber reinforced polymer bars in high-strength concrete", Composites Part B: Engineering, 39, pp. 258-270, 2008.

https://doi.org/10.1016/j.compositesb.2007.03.008

[35] Won, J.-P., Park, C.-G., Kim, H.-H., Lee, S.-W., Jang, C.-I. "Effect of fibers on the bonds between FRP reinforcing bars and high-strength concrete", Composites Part B: Engineering, 39, pp. 747-755, 2008. https://doi.org/10.1016/j.compositesb.2007.11.005

[36] Achillides, Z., Pilakoutas, K. "Bond behaviour of fiber reinforced polymer bars under direct pullout conditions", Journal of Composites for Construction, 8, pp. 173-181, 2004. https://doi.org/10.1061/(ASCE)1090-0268(2004)8:2(173)

[37] Tighiouart, B., Benmokrane, B., Gao, D. "Investigation of bond in concrete member with fibre reinforced polymer (FRP) bars", Construction and Building Materials, 12, pp. 453-462, 1998. https://doi.org/10.1016/S0950-0618(98)00027-0

[38] Veljkovic, A., Carvelli, V., Haffke, M. M., Pahn, M. "Concrete cover effect on the bond of GFRP bar and concrete under static loading", Composites Part B: Engineering, 124, pp. 40-53, 2017. https://doi.org/10.1016/j.compositesb.2017.05.054 
[39] Caro, M., Jemaa, Y., Dirar, S., Quinn, A. "Bond performance of deep embedment FRP bars epoxy-bonded into concrete", Engineering Structures, 147, pp. 448-457, 2017.

https://doi.org/10.1016/j.engstruct.2017.05.069

[40] Eligehausen, R., Popov, E. P., Bertero, V. V. "Local bond stressslip relationships of deformed bars under generalized excitations", In: Proceedings of the 7th European Conference on Earthquake Engineering, Athens, Greece, 1982, pp. 69-80. http://dx.doi.org/10.18419/opus-415

[41] Cosenza, E., Manfredi, G., Realfonzo, R. "Analytical Modeling of Bond between FRP Reinforcing Bars and Concrete", In: Non-Metallic (FRP) Reinforcement for Concrete Structures" - Proceedings of the Second International RILEM Symposium (FRPRCS-2), Ghent, Belgium, 1995, pp. 164-171.
[42] Cosenza, E., Manfredi, G., Realfonzo, R. "Behaviour and modeling of bond of FRP rebars to concrete", Journal of Composites for Construction, 1(2), pp. 40-51, 1997.

https://doi.org/10.1061/(ASCE)1090-0268(1997)1:2(40)

[43] Pecce, M., Manfredi, G., Realfonzo, R., Cosenza, E. "Experimental and analytical evaluation of bond properties of GFRP bars", Journal of Materials in Civil Engineering, 13, pp. 282-290, 2001. https://doi.org/10.1061/(ASCE)0899-1561(2001)13:4(282)

[44] Focacci, F., Nanni, A., Bakis, C. E. "Local bond-slip relationship for FRP reinforcement in concrete", Journal of Composites for Construction, 4(1), pp. 24-31, 2000.

https://doi.org/10.1061/(ASCE)1090-0268(2000)4:1(24) 